\title{
Experimental investigation into the flexural behaviour of basalt FRP reinforced concrete members
}

\author{
Rabee Shamass ${ }^{\text {a }}$, K.A. Cashell ${ }^{\mathrm{b}}$ \\ ${ }^{a}$ Division of Civil and Building Services Engineering, School of Build Environment and Architecture, London \\ South Bank University, UK \\ ${ }^{\mathrm{b}}$ Dept of Civil and Environmental Engineering, Brunel University London, UK
}

\begin{abstract}
The durability of reinforced concrete structures is an ongoing challenge for engineers, particularly in harsh environments. In these conditions, concrete is susceptible to excessive cracking which allows water or other aggressive agents to penetrate the structure, thereby accelerating the deterioration, mainly through corrosion, of the steel reinforcement. The deteriorated concrete structures require frequent maintenance to achieve and extend their service life and may need expensive rehabilitation measures. The use of fibre-reinforced polymer (FRP) rebars, such as carbon and glass FRPs, can be an effective, sustainable and durable solution to enhance the durability of reinforced concrete structures in aggressive environments. Another type of FRP that has gained popularity in construction in the last two decades is basalt fibre-reinforced polymer (BFRP), which is the subject of the current paper. In order to investigate their behaviour, an experimental programme comprising five reinforced concrete beams and seven one-way spanning slabs has been conducted, and is described herein in detail. Three different types of reinforcement were included in the tests, namely sand-coated BFRP bars, ribbed BFRP bars as well as regular carbon steel reinforcement, for comparison. All of the members were tested up until failure. The test results are presented and analysed, with particular focus given to the cracking moment, ultimate moment capacity, deflections and also crack opening widths. The results are compared with the guidance currently available in several international design codes. In addition, based on the results and analysis presented herein, design recommendations for reinforced concrete with BFRP rebars are proposed.
\end{abstract}

Keyword: Basalt-fibre-reinforced-polymer (BFRP); durability; Eurocode 2; flexural capacity; sustainability; design guidance. 


\section{Introduction}

The development of cracks is an inevitable phenomenon in concrete structural elements, which are subjected to tensile stresses. Cracking can reduce the load bearing capacity of the structure and also accelerate deterioration, thereby shortening the service life and increasing the inspection and maintenance costs. For reinforced concrete (RC), excessive cracking reduces the overall durability by allowing water and other aggressive agents to penetrate, thus accelerating the deterioration, mainly through corrosion, of the reinforcing steel. The corroded reinforcing steel has a reduced crosssectional area which results in a loss in the bearing capacity of the steel reinforced concrete member, as well as a reduction in the composite action between the constituent materials.

Research studies have shown that under excessive corrosion, reinforcing steel may suffer a significant loss of ductility [1] as well as a reduction in yield and ultimate strength [2]. In addition, there is likely to be a loss of bond strength, which may result in excessive cracking and spalling of the concrete, as well as pull-out failure of the rebars. In this respect, cracking of concrete and reduction in the crosssectional area of the rebar can endanger the safety and serviceability of RC structures. Chlorideinduced corrosion may occur in marine environments where the reinforced concrete structures are exposed to ocean salts, and may also occur inland when deicing salts come in to contact with the concrete surface of pavements and floors of parking garages [3]. The UK's Department of Transport (DoT) estimates that salt-induced corrosion damage costs around £616.5 million per year on motorway and trunk road bridges in England and Wales alone [4].

Unsatisfactory durability of concrete structures has not only severe economic impacts, since repairing deteriorated structures can cost almost as much as replacing them entirely, but also industrial, environmental and social challenges due to the reduction of reliability and safety [3]. With this in mind, construction and infrastructure faces a real challenge to improve the resilience, maintenance and rehabilitation of RC structures to minimise the cumulative cost to society. The use of fibre reinforced polymer (FRP) reinforcement, such as carbon (CFRP) and glass (GFRP), can be an effective, sustainable and durable solution to enhance the performance of RC structures in aggressive environments. Another type of FRP that has gained popularity in construction in the recent years is basalt fibre reinforced polymer (BFRP), which is the main subject of interest in the current paper. BFRP does not require the addition of any special additives during production; therefore, it is easier and cheaper to produce than other fibre types such as glass fibre [5].

The chemical stability of BFRPs is better than glass FRPs, especially under exposure to acids, and they have very good resistance to alkaline exposure [6] as well as corrosion from seawater [7]. There are many economic benefits of using BFRP in construction. The density of basalt is approximately 
one third of that of steel, which means less cost for transportation and lifting, and other associated construction costs. The tensile strength of BFRP rebars is much higher that the tensile strength of steel reinforcement and consequently, smaller concrete sections can potentially be designed. Furthermore, BFRP rebars do not corrode or absorb water in aggressive environments and therefore the concrete cover distance can be reduced. This is particularly useful in marine and bridge applications which currently require relatively large concrete cover distances, and therefore significant savings in construction and maintenance costs can be achieved. It has been estimated that the energy required for basalt fibre production is around $5 \mathrm{kWh} / \mathrm{kg}$ in an electric furnace, whereas the energy required to produce steel is around $14 \mathrm{kWh} / \mathrm{kg}$ [8]. It is expected that this saving in energy consumption will have an impact on the environmental performance of BFRP. BFRP reinforcement bars are therefore a promising material in concrete as a replacement for at least some steel and other types of FRP reinforcement.

There have been many studies into the behaviour of carbon and glass FRP reinforced concrete structures. Both have been shown to provide effective flexural and shear reinforcement for various reinforced concrete elements including RC beams (e.g. $[9,10])$ and slabs (e.g. $[11,12])$. On the other hand, there has been quite limited research into the behaviour of basalt BFRP rebars as a reinforcing material, and there is therefore very little design guidance available for engineers. One of the few studies that has been conducted found that the flexural capacity of simply-supported BFRP RC beams is higher than that of steel RC beams with a similar reinforcement ratio, geometry and concrete strength [13] and BFRP RC beams exhibit higher deflections than steel RC beams due to the lower elastic modulus of BFRP compared with steel. Duic et al. [14] tested BFRP RC beams and found that the BFRP RC beams are able to exhibit significant deformation before failure (i.e. deformability) and meet the Canadian highway bridge design code CSA-S6-14 [15] requirements for deformability.

There are a number of international design codes for FRP reinforced concrete including the American ACI 440.1 R-06 [16], Canadian CSA S806-02 [17] and Russian SP295 [18] standards. These are applicable for the design of concrete members reinforced with carbon, glass and aramid FRP bars and do not yet include any recommendations for BFRP reinforcement because of the lack of available performance data. There is no existing European or British standard for the design of RC elements reinforced with FRP rebar. The closest technical document is the fib Bulletin No. 40 [19], which adopts the framework of Eurocode 2 [20] for the evaluation of ultimate moment capacity of FRP RC members. Nevertheless, the fib Bulletin does not yet include any design recommendations for BFRP RC members. 
In general, like standard reinforced concrete beams, the failure mode of BFRP RC beams is governed by the reinforcement ratio. When the reinforcement ratio is increased beyond the balanced reinforcement ratio (that is, the ratio where concrete crushing and FRP rupture occur simultaneously) according to the ACI design standard [16], the beam fails by concrete crushing [21]. This type of failure is not sudden since the beam exhibits some ductility before the limit is reached [22]. Also, over-reinforced BFRP RC beams exhibit fewer shear cracks compared with standard carbon steel reinforced concrete beams [14]. On the other hand, when the reinforcement ratio is relatively low, and below the balanced reinforcement ratio, the beams fail suddenly due to bar rupture [22], and a greater number of flexural and shear cracks are observed compared to steel RC beams with a similar reinforcement ratio [14]. It was found that when the ACI [16] design code for concrete reinforced with FRP is applied for BFRP reinforced concrete members, it generally overestimates the cracking moment [23], provides an accurate estimation of the bending moment capacity [24], and underestimates the deflections due to its overestimation of the effective moment rigidity of the crosssection; therefore, a modified effective moment rigidity was proposed to accurately predict the defection obtained experimentally [24].

The application of BFRP bars has been extended to include continuous slabs under static loading [12], and one-way slabs under sudden explosive loading [25]. It was found that BFRP reinforced continuous slabs develop earlier and wider cracks and greater deflections compared to those reinforced with steel, and the ACI code [16] underestimates the BFRP slab deflections and overestimates the bending moment capacity at the supports and mid-span. However, when the slabs are over-reinforced at both the supports and the mid-span, a higher loading capacity and reduced level of deflection was observed [12].

In this context, given the considerable advantages and acknowledged challenges of using BFRP in reinforced concrete members, the main objective of this study is to experimentally investigate the flexural behaviour of full-scale, simply-supported concrete beams and one-way spanning slabs which are internally reinforced with either steel or BFRP reinforcement. Two of the most common, commercially available, types of basalt bars are used in this investigation, namely the sand-coated and ribbed surface reinforcement. Particular attention is given to the cracking moment, flexural capacity, crack widths at the service load, and deflections, and each of these values obtained experimentally are compared with those predicted using the American, Canadian, Russian and European design standards, to check if BFRP reinforced concrete members comply with the requirements of current FRP standards. Based on the findings of this study, guidance for engineers designing RC members with BFRP, is presented. 


\section{Experimental programme}

A total of 12 tests on reinforced concrete members including 5 beams and 7 slabs were conducted in the structural engineering laboratory at London South Bank University. Two different types of BFRP were included in the study, sand-coated BFRPs and ribbed BFRPs, as well as regular steel reinforcement, for comparison. Fig. 1 presents an image of the BFRPs used in the current study. The following sub-sections will provide details on the properties of the different materials used in the study, as well as other key experimental aspects.

\subsection{Test materials}

\subsubsection{Reinforcement}

A number of different types of reinforcement were used in the experimental programme, which are summarised in Table 1. For the beam specimens, the tensile reinforcement in the lower region of the beams was either sand-coated BFRP bars, ribbed BFRP bars or steel bars, all with a diameter of $10 \mathrm{~mm}$. The specimens also included shear links and top reinforcement which was made from $8 \mathrm{~mm}$ steel bars. On the other hand, the one-way spanning slab specimens were reinforced in the longitudinal direction with either (i) sand-coated basalt FRP bars with a diameter of either $6 \mathrm{~mm}$ or $10 \mathrm{~mm}$, (ii) ribbed basalt bars with a diameter of either 10 or $12 \mathrm{~mm}$, or (iii) steel bars with a diameter of $10 \mathrm{~mm}$. In all cases, $8 \mathrm{~mm}$ steel bars were used in the transversal direction.

The mechanical properties of each reinforcement type used in the experimental campaign was obtained through tensile testing, and the key characteristic properties including the elastic modulus $(E)$, ultimate tensile strength $\left(f_{u}\right)$ and yield strength $\left(f_{y}\right)$ for the steel bars, as are given in Table 1 . The mechanical property values presented in Table 1 are the average of five tested samples. In addition, it is noteworthy that there are no yield strength values presented for the BFRP bars as these materials do not exhibit a yield point, as seen in the typical stress-strain curves shown in Fig. 2.

\subsubsection{Concrete}

The beam and slab specimens were made with normal strength concrete which had a target compressive strength of C30/37 MPa and slump of $150 \mathrm{~mm}$. The concrete mix was designed accordingly using $463 \mathrm{~kg} / \mathrm{m}^{3}$ of cement, $700 \mathrm{~kg} / \mathrm{m}^{3}$ of sand and $927 \mathrm{~kg} / \mathrm{m}^{3}$ of aggregate with a water/cement ratio $(\mathrm{w} / \mathrm{c})$ of $54 \%$. The maximum aggregate size was $10 \mathrm{~mm}$. A number of $100 \times 100 \times 100 \mathrm{~mm}$ concrete cubes were also cast using the same mix. These were tested on the day of specimen testing, using at least three samples, and the average compressive strength values $\left(\mathrm{f}_{\mathrm{cu}}\right)$ from these tests are given in Table 2. The image presented in Fig. 3 shows a specimen mould just before casting, with the rebar in position, and also a beam just after the concrete was cast. 


\subsection{Test specimens}

\subsubsection{Beams}

A total of 5 reinforced concrete beams were examined in the test programme, as listed in Table 2, including two with sand-coated basalt FRP reinforcement (SA-B10-1 and SA-B10-2), two with ribbed basalt FRP bars (R-B10-1 and R-B10-2) and one with regular steel rebars (S-B10-1). A reference-system was adopted to label each specimen, where the first portion of the name denotes the type of rebar used (i.e. sand-coated basalt FRP (SA), ribbed basalt FRP (R) and steel reinforcement $(\mathrm{S})$ ), the next term between the two hyphens defines if the specimen is a beam (B) or slab (S) and the diameter of the tension reinforcement $(10 \mathrm{~mm}$ or $6 \mathrm{~mm})$ and the final portion is the specimen number. Fig. 4(a) presents a schematic of the test beams and an image of the moulds used for casting, is shown in Fig. 4(b).

All of the beams were $200 \mathrm{~mm}$ in height, $125 \mathrm{~mm}$ in width and had an overall length of $2000 \mathrm{~mm}$. The beams were tested under four-point bending loading conditions over a clear span of $1800 \mathrm{~mm}$ and the distance between the two loading points (denoted as P in Fig. 4) was $500 \mathrm{~mm}$ (i.e. this is the length of the constant moment zone in the middle of the beam). The cover distance from the outer edge of the specimens to the reinforcement was $15 \mathrm{~mm}$ at the beam ends and $25 \mathrm{~mm}$ on the top and bottom of the beam. All of the beams included steel shear links, which were $8 \mathrm{~mm}$ in diameter. They were spaced at $100 \mathrm{~mm}$ intervals in the shear spans and at $200 \mathrm{~mm}$ intervals in the constant moment zone, as shown in Fig. 4. The beams were reinforced with two $8 \mathrm{~mm}$ steel rebars as top reinforcement and two $10 \mathrm{~mm}$ rebars (either sand-coated BFRP, ribbed BFRP or steel) as tensile reinforcement.

The reinforcement ratio $\left(\rho_{f}\right)$ is considered balanced $\left(\rho_{b}\right)$ when the quantity of FRP reinforcement and concrete is such that concrete crushing and reinforcement rupture occur simultaneously. It is calculated based on the equilibrium of internal forces and the mechanical properties of the constituent materials. All of the BFRP RC beams in the current programme were designed to fail by concrete crushing using a reinforcement ratio, which was greater than $\rho$ b. The American ACI 440.1R-06 [16] , Canadian CSA-S806-02 [17] and Russian SP295 [18] design codes for the design of FRP RC structures propose Eq. 1-3, respectively, to calculate the balanced reinforcement ratio (i.e. $\rho$ b,ACI, $\rho b, C A N, \rho b, R U S$ respectively). These standards replace the non-linear stress distribution of concrete with an equivalent rectangular stress block. Using the equivalent rectangular stress block proposed in Eurocode 2 [20] and assuming that the strain in the concrete and reinforcement equals the crushing and ultimate strains, respectively, application of the equilibrium of internal forces results in the balanced reinforced ratio $(\rho \mathrm{b}, \mathrm{EC} 2)$ presented in Eq. 4. Pilakoutas et al. [26] proposed another expression for a balanced reinforcement ratio in BFRP beams ( $\left.\rho_{b}, \mathrm{Pil}\right)$ using the framework of 
Eurocode 2 (Eq. 5), however, it provides very high values of $\rho_{\mathrm{b}}$ compared with Eqs. 1-4, which results in uneconomical BFRP RC sections. Therefore, it is not used in the current study.

$$
\rho_{\mathrm{b}, \mathrm{ACI}}=0.85 \beta_{1} \frac{\varepsilon_{\mathrm{cu}}}{\varepsilon_{\mathrm{cu}}+\varepsilon_{\mathrm{fu}}} \frac{\grave{\mathrm{f}}_{\mathrm{c}}}{\mathrm{f}_{\mathrm{u}}}
$$

where: $\beta_{1}=0.85-0.05 \frac{\hat{f_{c}}-27.6}{6.9}$

$$
\rho_{\mathrm{b}, \mathrm{CAN}}=\alpha_{1} \beta_{1} \frac{\varepsilon_{\mathrm{cu}}}{\varepsilon_{\mathrm{cu}}+\varepsilon_{\mathrm{fu}}} \frac{\grave{\mathrm{f}}}{\mathrm{f}_{\mathrm{u}}}
$$

where: $\alpha_{1}=0.97-0.0025 \grave{f}_{\mathrm{c}} \geq 0.67 ; \quad \beta_{1}=0.85-0.0015 \grave{f}_{\mathrm{c}} \geq 0.67$

$$
\begin{gathered}
\rho_{\mathrm{b}, \mathrm{RUS}}=0.8 \frac{\grave{\mathrm{f}}_{\mathrm{c}}}{\mathrm{f}_{\mathrm{u}}\left(1+\frac{\varepsilon_{\mathrm{fu}}}{\varepsilon_{\mathrm{cu}}}\right)} \\
\rho_{\mathrm{b}, \mathrm{EC} 2}=\frac{\lambda \eta \grave{\mathrm{f}}_{\mathrm{c}} \varepsilon_{\mathrm{cu}}}{\mathrm{f}_{\mathrm{u}}\left(\varepsilon_{\mathrm{fu}}+\varepsilon_{\mathrm{cu}}\right)} \\
\rho_{\mathrm{b}, \text { Pil }}=0.81 \frac{\left(\grave{\mathrm{f}}_{\mathrm{c}}+8\right) \varepsilon_{\mathrm{cu}}}{\mathrm{f}_{\mathrm{u}}\left(\varepsilon_{\mathrm{fu}}+\varepsilon_{\mathrm{cu}}\right)}
\end{gathered}
$$

In these expressions, $\mathrm{f}_{\mathrm{c}}$ is the cylindrical compressive strength of concrete and is taken as $0.81 \mathrm{f}_{\mathrm{cu}}, \varepsilon_{\mathrm{cu}}$ is the ultimate compressive strain of concrete $(0.003$ for the American guide and 0.0035 for the Canadian, Russian and Eurocode standards), $\mathrm{f}_{\mathrm{u}}$ and $\varepsilon_{\mathrm{fu}}$ are the ultimate tensile stress and strain, respectively, of the BFRP rebar, and $\lambda$ and $\eta$ are factors relating to the equivalent rectangular stress blocks in the concrete and are taken as 0.8 and 1 , respectively, for $\hat{f}_{c} \leq 50 \mathrm{MPa}$, in accordance with Eurocode 2.

The reinforcement ratios for a balanced section according to each of the previously discussed design codes are presented in Table 2. It can be seen that the values predicted by the Canadian CSA, Russian SP295 and Eurocode 2 codes are very similar to each other whilst American ACI provides the lowest $\rho b$ ratio predictions. Similar observations were found by Elgabbas et al. [23] where the American code was found to predict $\rho b$ ratios lower than those from the Canadian standard.

\subsubsection{Slabs}

A total of seven, one-way spanning reinforced concrete slabs were tested in the experimental programme, and the details of each are presented in Table 2. The specimens are labelled using a 
similar reference system as before, and there were three specimens with sand-coated basalt FRP reinforcement (SA-S6-1, SA-S6-2, and SA-S10-1), two with ribbed basalt FRP bars (R-S10-1 and RS12-1) and two with regular steel bars (S-S10-1 and S-S10-2). There were three different bar geometries tested including 6, 10 and $12 \mathrm{~mm}$ bars. The slabs all had identical geometries and were $800 \mathrm{~mm}$ in length, $300 \mathrm{~mm}$ in width and had a depth of $75 \mathrm{~mm}$. They were tested under three-point bending over a clear span of $700 \mathrm{~mm}$, as shown in Fig. 5(a), with a point load (P) applied at the midspan. An image from the moulds used for casting is presented in Fig. 5(b).

Three reinforcing bars (either sand-coated basalt FRP, ribbed basalt FRP or steel) were used as tensile reinforcement in the longitudinal direction of each slab with a spacing of $110 \mathrm{~mm}$ between each bar. The cover distance between these bars and the bottom, and sides, of the slab was $25 \mathrm{~mm}$. In the transverse direction, three $8 \mathrm{~mm}$ steel rebars were placed in each slab, as shown in Fig. 5(b). To avoid the BFRP bars floating during concrete casting, they were fixed to the base of the wooden mould.

Similarly to the beam specimens, all of the slabs in this test programme were designed to fail by concrete crushing by adopting a reinforcement ratio which was greater than the balanced reinforcement ratio, $\rho_{\mathrm{b}}$. The $\rho_{\mathrm{b}}$ values predicted by the American, Canadian, Russian and Eurocode standards (i.e. $\rho_{b}, \mathrm{ACI}, \rho_{b}, \mathrm{CAN}, \rho_{b}, \mathrm{RUS}$ and $\rho_{b, \mathrm{EC} 2}$ respectively) for BFRP reinforcement are presented in Table 2.

\subsection{Instrumentation and testing procedure}

The specimens were tested 28 days after the concrete was cast. Both the beams and the slabs were painted white before testing to facilitate clear observation of the crack development. The tests were conducted in deflection control at a rate of $1 \mathrm{~mm} / \mathrm{min}$ until failure using a $250 \mathrm{kN}$ hydraulic testing machine in the structures laboratory at London South Bank University. The vertical deflection at the mid-span of the beams and slabs was recorded using linear variable differential transducers (LVDTs). An automatic data acquisition system connected to a computer was used to monitor loading and deflections. During testing, the first crack was visually observed and the corresponding load was recorded to obtain the cracking moment. The crack propagation and distribution along the beams and slabs were monitored during the tests, and the average crack widths of the first two visible cracks were measured. Once the first two cracks were visible in the beams and slabs during loading, the test was paused and two metal strips were glued on both sides of each crack and the average crack width was obtained by recording the separation of the metal strips using digital Vernier dial gauge. The tests were then re-started and the crack widths were recorded at every $5 \mathrm{kN}$ load increment for the beams and $1 \mathrm{kN}$ load increment for the slabs. 


\section{Test results and discussion}

In this section, the main observations and analysis of the test results are presented. There are a number of important performance measures for reinforced concrete flexural members and each is discussed, in detail, with reference where appropriate to international design codes. The phenomena which are discussed hereafter include (1) load-deflection response, (2) cracking moment, (3) ultimate capacity, (4) crack patterns, (5) deflections and (6) crack widths.

\subsection{Load-deflection behaviour}

The load-deflection response for all of the reinforced concrete beams is presented in Fig. 6 whilst the same curves for the one-way spanning slabs are given in Fig. 7. In the following sub-sections, the beam behaviour is first analysed, followed by the slabs.

\subsubsection{Beam specimens}

Fig. 6 presents the load versus mid-span deflection for all five of the tested RC beams. It was observed that all BFRP RC beams or and slabs behaved similarly until the first crack occurred. All of the beams failed, as designed, by crushing of the concrete. Initially, the response was very similar for all five specimens. However, after 1-2 $\mathrm{mm}$ of deflection, it is very clear that the stiffness of the steel reinforced beam (S-B10-1) was much greater than that of the BFRP elements owing to the much higher elastic modulus of steel compared with BFRP; it is around 3.6 times higher for steel (as given in Table 1). The beam S-B10-1 exhibited quite linear behaviour until the stress in the steel reached its yield stress at around $40 \mathrm{kN}$ of applied load, and this was then followed by a short yield plateau and slight increase in the loading capacity due to strain hardening in the steel rebar. A number of cracks developed during the response, as evidenced by the short drops in load carrying capacity, which were almost immediately recovered. Following the initial cracking phase, the BFRP RC beams exhibited linear behaviour until the ultimate load followed by a sudden failure of the beams due to concrete crushing. It is also noticeable that the two beams reinforced with sand-coated BFRP exhibited slightly a stiffer response than those with ribbed BFRP. This is likely to be due to greater levels of bond developing in the sand-coated rebars, as both types of BFRP have very similar elastic moduli.

With reference to Fig. 6 and the data presented in Table 4, it is shown that S-B10-1 underwent much lower deflections compared with the four beams with BFRP. For instance, the deflection at the ultimate load for beams SA-B10-1 and R-B10-1 was 255\% and 319\% higher than the deflection at the ultimate load for S-B10-1, respectively. This is mainly owing to the greater stiffness of the steel 
rebars compared with the BFRP and the BFRP beams were designed to avoid the rupture of BFRP; all five beams failed in the same manner, by concrete crushing.

\subsubsection{Concrete slabs}

Fig. 7 presents the load-deflection responses for the seven one-way spanning slabs, as detailed in Table 2. In this case, the behaviour was very different for the steel reinforced member compared with BFRP RC slabs. The following key observations can be made based on the responses in the figure:

- In general, the load-deflection responses for the members reinforced with BFRP were quite similar to each other. However, it is notable that the failure deflections for the slabs with sandcoated rebars was higher than those for the ribbed BFRP. This will be discussed in more detail in Section 3.5 of this paper.

- Specimen S-S10-1 exhibited linear behaviour until the stress in the steel reached its yield strength value, and this was followed by long yield plateau at which the deflection increased without any change in the applied load. On the other hand, the slabs reinforced with BFRP bars exhibited quite a linear response until failure, which occurred when the concrete reached is ultimate strength and crushed.

- It is evident from Fig. 7 that the slabs SA-S6-1 and SA-S6-2 exhibited much lower stiffness and ultimate load compared with the other slabs, although they also exhibited more deformability. This is because these slabs had the lowest reinforcement ratio of the BFRP reinforced slabs.

- After around 1-2 mm of deflection, the behaviour of the slabs is quite similar to that of the beams in that the bending stiffness of the steel RC slabs was much greater than that of the BFRP RC slabs.

- It is shown that as the reinforcement ratio of the BFRP RC slabs increases, the bending stiffness also increases quite significantly. For example, as given in Table 2, the reinforcement ratio $(\rho$ f) for SA-S10-1 was 0.0142 whilst for SA-S6-1 it was 0.0062 , representing an increase of $130 \%$. This resulted in a bending stiffness, which was around twice as stiff for SA-S10-1 than for SA-S6-1.

- Slabs S-S10-1 and S-S10-1 reached much higher loads than the BFRP reinforced members, which is the opposite finding to that which occurred for the beams. One possible explanation for this is that the strain in the BFRP reinforcement is lower in the slabs relative to the beams due to their higher reinforcement ratio. This is discussed further in Section 3.3.2.

\subsection{Cracking moment}


The bending moment corresponding to the first visible crack for each RC member was recorded, and these values are presented in Table 3 ( $\mathrm{M}_{\mathrm{cr} \text { Exp }}$ ). The average cracking moment for BFRP RC beams and slabs was $2.2 \mathrm{kNm}$ and $0.93 \mathrm{kNm}$, respectively. The cracking moment for the BFRP RC beams ranged from $11.5 \%$ to $17.4 \%$ of the ultimate moment for each beam while the cracking moment for the BFRP RC slabs varied between $20.5 \%$ and $22.2 \%$ of the ultimate moment capacity.

Since the elastic modulus of steel is significantly higher than that of BFRP (as presented in Table 1), the cracking moment for the RC members with steel reinforcement was higher than those with BFRP by around $29 \%$ and $86 \%$ for the beams reinforced with sand-coated and ribbed BFRP, respectively, and $58 \%$ and $71 \%$ for the slabs reinforced with sand-coated and ribbed BFRP, respectively. Additionally, the sand-coated BFRP RC members exhibited greater cracking moments than the ribbed BFRP RC members, even for the same bar diameter, by around $31 \%$ for the beams and $17 \%$ for the slabs. This is likely to be due to different bonding between the two types of BFRP and the surrounding concrete.

The cracking moment can be calculated using the expression given in Eq. 6, as follows:

$$
\mathrm{M}_{\mathrm{cr}}=\frac{\mathrm{f}_{\mathrm{r}} \mathrm{I}_{\mathrm{g}}}{\mathrm{y}_{\mathrm{t}}}
$$

where $\mathrm{I}_{\mathrm{g}}$ is the gross moment of inertia, $\mathrm{y}_{\mathrm{t}}$ is the vertical distance between the extreme tension fibres and the neutral axis, and $f_{r}$ is the modulus of rupture of the concrete. The $f_{r}$ value can be calculated using Eq. 7, 8, 9, 10 in accordance with the American ACI 440.1R-06 [16], Canadian CSA-S806-02 [17], Russian SP295 [18] and European EN 1992-1-1 [20] design codes, respectively, to give:

$$
\begin{aligned}
& \mathrm{f}_{\mathrm{r}, \mathrm{ACI}}=0.62 \sqrt{\hat{\mathrm{f}}_{\mathrm{c}}} \\
& \mathrm{f}_{\mathrm{r}, \mathrm{CAN}}=0.6 \sqrt{\mathrm{f}_{\mathrm{c}}} \\
& \mathrm{f}_{\mathrm{r}, \mathrm{RUS}}=0.23\left(\mathrm{f}_{\mathrm{cu}}^{150}\right)^{2 / 3} \\
& \mathrm{f}_{\mathrm{r}, \mathrm{EC} 2}=0.3\left(\hat{\mathrm{f}}_{\mathrm{c}}\right)^{2 / 3}
\end{aligned}
$$

In these expressions, $\mathrm{f}_{\mathrm{cu}}^{150}$ is the compressive strength of concrete measured using $150 \mathrm{~mm}^{3}$ cubes and is taken as $0.95 \mathrm{f}_{\mathrm{cu}}[27]$ in the current work. 
Table 3 presents the cracking moment predicted by each of the international design codes $\left(\mathrm{M}_{\mathrm{cr}, \mathrm{ACI}}\right.$, $\mathrm{M}_{\mathrm{cr}, \mathrm{CAN}}, \mathrm{M}_{\mathrm{cr}, \mathrm{RUS}}$ and $\mathrm{M}_{\mathrm{cr}, \mathrm{EC} 2}$ for the American, Canadian, Russian and European standards, respectively) together with the experimental values. It is clear that the accuracy of the predictions is quite variable depending on the type of element (beam or slab), reinforcement type (steel or BFRP) and BFRP type (sand-coated or ribbed). In general, the American, Canadian and European codes are more on the unconservative side (i.e. an overestimate of the cracking moment) than the Russian code, in that they overestimate the cracking moment whereas the Russian code underestimates the cracking moment in all but two cases. The average predicted-to-experimental cracking moments for all members are 1.13, 1.09, 0.8, and 0.95 for the ACI [16], CSA [17], SP295 [18], and Eurocode 2 [20] standards, respectively. Similarly, Table A.1 presents the cracking moments for the tested beams predicted by each of the international design codes together with the tests results of Elgabbas et al. [23], for comparison. It is observed that the American, Canadian and European standards overestimate the cracking moments compared with those that occurred in the tests. A factor that contributes to the unconservativeness of the calculated cracking moment is that none of the codified expressions presented allow for the effect of restrained shrinkage, which tends to reduce the experimental cracking moment. It is interesting to note that all of the codes are generally more unconservative for the beam cracking moment predictions compared with the slab behaviour, and also all four of the codes provides conservative prediction for the three specimens reinforced with steel rebars, especially for the slab elements.

For the members reinforced with sand-coated BFRP, all of the codes apart from the Russian code provide an unconservative estimation of the cracking moment except for the slab reinforced with $10 \mathrm{~mm}$ BFRP. In this case, all four of the codes provide conservative predictions with $\mathrm{M}_{\mathrm{cr}} / \mathrm{M}_{\mathrm{cr}, \operatorname{Exp}}$ values equal to $0.88,0.85,0.63$ and 0.74 for the American, Canadian, Russian and European standards, respectively. It is likely that the in inaccuracy and variation in these predictions is due to the respective moduli of rupture values that are adopted in the codes. The cracking moments for the beams that are reinforced with ribbed FRP are very unconservatively predicted by the American, Canadian and European codes and more accurately, yet unconservatively, estimated by the Russian code. This is due to the fact that the Russian code provides a lower estimation for modulus of rupture than that estimated by the other codes. However, for the slabs, the predictions are closer to the real

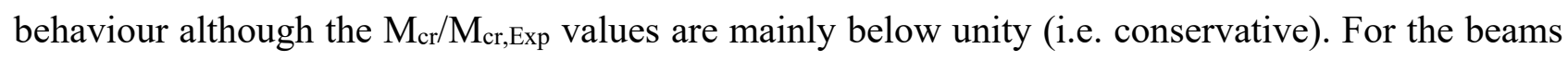
and slabs made using steel rebars, the codes underestimate the real cracking moment in all cases, most significantly for the slabs.

\subsection{Ultimate capacity}


The design philosophy for FRP reinforced concrete is based on the principles of equilibrium, strain compatibility, and the stress-strain relationship of concrete and the FRP. Concrete crushing or FRP rupture are the mechanisms that control failure of the section. For concrete crushing, a rectangular stress block is used to approximate the concrete stress distribution in the section, and to determine the load at which the ultimate strength is reached. On the other hand, the stress in the FRP is obtained through the compatibility of strains. The height and the stress value of the rectangular compressive stress block differs between the different design standards. Concrete compression failure is generally considered to be the more desirable failure mode since FRP failure is sudden and catastrophic. However, both failure modes are acceptable in the design of FRP RC flexural members provided that the strength and serviceability criteria are satisfied. The warnings associated with imminent FRP rupture include excessive cracking and large deflections while for concrete failure, the member usually has quite good deformability, with the section exhibiting pseudo-plastic behaviour before failure [28].

\subsubsection{Design standards}

The American, Canadian, Russian and European standards each contain expressions for calculating the design moment capacity of FRP reinforced concrete beams and slabs. These are presented in Eqs. 11-14 to give $\mathrm{M}_{\mathrm{ult}, \mathrm{ACl}}, \mathrm{M}_{\mathrm{ult}, \mathrm{CAN}}, \mathrm{M}_{\mathrm{ult}, \mathrm{RUS}}$ and $\mathrm{M}_{\mathrm{ult}, \mathrm{EC} 2}$, respectively:

$$
\begin{aligned}
& M_{u l t, A C I}=\rho_{\mathrm{f}} \mathrm{f}_{\mathrm{f}}\left(1-0.59 \frac{\rho_{\mathrm{f}} \mathrm{f}_{\mathrm{f}}}{\hat{f}_{\mathrm{c}}}\right) b d^{2} \\
& \text { where, } \mathrm{f}_{\mathrm{f}}=\left(\sqrt{\frac{\left(\mathrm{E}_{\mathrm{f}} \varepsilon_{\mathrm{cu}}\right)^{2}}{4}+\frac{0.85 \beta_{1} \hat{f}_{\mathrm{c}}}{\rho_{\mathrm{f}}} E_{\mathrm{f}} \varepsilon_{\mathrm{cu}}}-0.5 \mathrm{E}_{\mathrm{f}} \varepsilon_{\mathrm{cu}}\right) \leq \mathrm{f}_{\mathrm{u}} \\
& \mathrm{M}_{\mathrm{ult}, \mathrm{CAN}}=\alpha_{1} \beta_{1} \mathrm{f}_{\mathrm{c}} \mathrm{cb}\left(\mathrm{d}-\frac{\beta_{1} \mathrm{c}}{2}\right) \\
& \text { where, c }=\frac{\rho_{\mathrm{f}} \mathrm{f}_{\mathrm{f}}}{\alpha_{1} f_{\mathrm{c}} \beta_{1}} \mathrm{~d} \\
& \text { and } \mathrm{f}_{\mathrm{f}}=\left(\sqrt{\frac{\left.\mathrm{E}_{\mathrm{f}} \varepsilon_{\mathrm{cu}}\right)^{2}}{4}+\frac{\alpha_{1} \beta_{1} f_{\mathrm{c}}}{\rho_{\mathrm{f}}} \mathrm{E}_{\mathrm{f}} \varepsilon_{\mathrm{cu}}}-0.5 \mathrm{E}_{\mathrm{f}} \varepsilon_{\mathrm{cu}}\right) \leq \mathrm{f}_{\mathrm{u}} \\
& \mathrm{M}_{\mathrm{ult}, \mathrm{RUS}}=\mathrm{f}_{\mathrm{c}} \mathrm{bx}\left(\mathrm{d}-\frac{\mathrm{x}}{2}\right)
\end{aligned}
$$




$$
\begin{aligned}
& \text { where, } x=\sqrt{\left(0.5 \rho_{\mathrm{f}} \frac{E_{\mathrm{f}}}{\left(\hat{f}_{\mathrm{c}}^{\prime} / \varepsilon_{\mathrm{cu}}\right)} \mathrm{d}\right)^{2}+0.8 \rho_{\mathrm{f}} \frac{\mathrm{E}_{\mathrm{f}}}{\left(\mathrm{f}_{\mathrm{c}} / \varepsilon_{\mathrm{cu}}\right)} d^{2}}-0.5 \rho_{\mathrm{f}} \frac{\mathrm{E}_{\mathrm{f}}}{\left(\hat{f}_{\mathrm{c}} / \varepsilon_{\mathrm{cu}}\right)} \mathrm{d} \\
& \mathrm{M}_{\mathrm{ult}, \mathrm{EC} 2}=\eta \alpha_{c c} \hat{f}_{\mathrm{c}} \mathrm{bd} \mathrm{d}^{2}(\lambda \xi)\left(1-\frac{\lambda \xi}{2}\right)
\end{aligned}
$$$$
\text { where, } \xi=\frac{\varepsilon_{\mathrm{cu}}}{\varepsilon_{\mathrm{f}}+\varepsilon_{\mathrm{cu}}} \text { and }
$$$$
\varepsilon_{\mathrm{f}}=\frac{-\varepsilon_{\mathrm{cu}}+\sqrt{\varepsilon_{\mathrm{cu}}^{2}+\frac{4 \alpha_{c c} \hat{f}_{\mathrm{c}} \lambda \eta \varepsilon_{\mathrm{cu}}}{\rho_{\mathrm{f}} \mathrm{E}_{\mathrm{f}}}}}{2}
$$

In these expressions, the partial material factors are taken as unity and $\lambda$ and $\eta$ are taken as 0.8 and 1 , respectively, for $f_{c} \leq 50 \mathrm{MPa}$, in accordance with Eurocode 2 [20]. $\alpha_{c c}$ is taken as 0.85 as recommended by the UK National Annex to Eurocode 2 [20], b is the width of the cross-section, $d$ is the effective depth from the top of a reinforced concrete beam/slab to the centroid of the tensile reinforcement, Ef is the elastic modulus of BFRP, and $\mathrm{f}_{\mathrm{f}}$ and $\varepsilon_{\mathrm{f}}$ are the stress and strain in the BFRP reinforcing bars. It is noteworthy that, according to fib [19], the ultimate moment resistance values for FRP RC sections presented in Eq. 14 (Mult,EC2) are derived by adopting the rectangular stress distribution proposed in Eurocode 2.

\subsubsection{Comparison with test results}

Table 3 presents the moment capacities of BFRP RC beams and slabs obtained experimentally $\left(M_{u l t, E x p}\right)$ with those predicted by the various design codes $\left(M_{u l t, A C l}, M_{u l t, C A N}, M_{u l t, R U S}\right.$ and $M_{u l t, E C 2}$ for the American, Canadian, Russian and European standards, respectively). For steel reinforced concrete members, the analytical bending capacity are calculated using only Eurocode 2 . It is evident that for BFRP and steel RC beams with the same reinforcement ratio, the experimental moment capacity of the BFRP RC beams is higher than that of the steel RC beams by an average of around $12 \%$. Furthermore, the American ACI 440.1R-06 [16] code provide acceptable predictions of the bending moment capacity while Eurocode 2 [20] and Canadian CSA S806-02 [17] codes slightly overestimates the bending moment capacity by an average of 7\% and the Russian code SP295 [18] overestimates the moment capacity by an average of 16.5\%. On the other hand, Elgabbas et al. [23] found that both the American ACI 440.1R-06 [16] and Canadian CSA S806-02 [17] standards underestimate the ultimate moment observed experimentally for BFRP reinforced beams (see Table A.1) while Abed and Alhafiz [29] observed that the ACI code [16] provides an acceptable bending 
moment capacity for most tested BFRP beams. For the same beams tested by Elgabbas et al. [23] and presented in Table A.1, it can be seen that Eurocode 2 [20] underestimates the bending moment capacity while the Russian code SP295 [18] also underestimates the bending capacity in all but two cases. The differences in the bending moment predictions given by the ACI [16], CSA [17], SP295 [18] and Eurocode 2 [20] are related to the assumed height of the compressive rectangular stress block in the concrete and the assumed strain at the ultimate condition which is 0.003 for the ACI code [16] and 0.0035 for the CSA [17], SP295 [18] and Eurocode 2 [20] standards resulting in lower bending moment predictions using the ACI code [16] and slightly higher predictions for the CSA standard [17] and Eurocode 2 [20].

For RC slab members, it is interesting to note that the steel RC slabs exhibit higher moment capacity than the BFRP RC slabs by about $24 \%$. As stated before, this is the opposite finding to that which was observed for the beams where the BFRP reinforced members had a greater capacity than those reinforced with traditional steel. One possible explanation is that BFRP reinforcement ratio for the slabs is higher than that for the beams resulting in an increase in the neutral axis depth, which reduces the strain in the reinforcement corresponding to a particular crushing strain at the top fibre. The slabs reinforced with steel rebars were possibly able to develop greater catenary action, owing to the particular bond and cracking regime, which developed in these specimens. Furthermore, increasing the reinforcement ratio of the BFRP reinforced concrete slabs has no significant influence on the flexural capacity of the member since the dominant failure mode is crushing of the concrete. However, the deflections and the bending stiffness for BFRP slabs showed a significant reduction for the slabs with higher reinforcement ratios, as seen in Fig. 5. For example, for specimen SA-S6-1, which had a reinforcement ratio of 0.0062 , the bending capacity and deflection at failure as well as the bending stiffness have values of $3.8 \mathrm{kNm}, 21.3 \mathrm{~mm}$ and $112 \mathrm{kNm} / \mathrm{m}$, respectively, while the corresponding values for SA-S10-1 $\left(\rho_{\mathrm{f}}=0.0142\right)$ are $4.7 \mathrm{kNm}, 16.4 \mathrm{~mm}$ and $219 \mathrm{kNm} / \mathrm{m}$. Furthermore, the American, Canadian and European design codes provide a conservative but acceptable prediction for the flexural capacity of one-way slabs while the Russian code provides the most accurate flexural capacity predictions.

\subsection{Crack pattern}

Fig. 8(a-d) presents a schematic view of the propagation of cracks with increasing load, as well as the final crack pattern, for specimens S-B10-1, R-B10-1, S-S10-1 and SA-S10-1, respectively. These specimens are selected for illustrative purposes and similar analyses has been conducted for all of the other test specimens. The propagation of cracks and the crack patterns of the steel and BFRP RC beams are similar, as shown in the Figs. 8(a) and (b). The first cracks appear in the region of pure 
tension and then propagate vertically upwards towards the compression zone. As the load increases, more cracks develop further away from the constant-moment region towards the supports and then propagate diagonally towards the loading points because of the combination of flexural and shear stresses in this region. It can be seen that the cracks that developed in beam R-B10-1 (with ribbed basalt FRP rebars) were longer in length than those for S-B10-1 (steel rebars) at the same loading level. Furthermore, at the ultimate load, the BFRP RC beams failed by concrete crushing whereas the steel RC beams fails by steel yielding. This is a positive outcome for the BFRP bars as compressive failure is a more favourable failure mode compared with rebar rupture.

The cracking behaviour between the BFRP and steel reinforced slabs was noticeably quite different. In both cases, the first cracks in the slab specimens S-S10-1 and SA-S10-1 appeared in the centre of the member directly under the point load (as shown for specimens S-S10-1 and SA-S10-1 in Fig. 8(c) and (d)). Then, as the loading increased, the cracks generally propagated vertically as well as diagonally towards the loading point. Slab S-S10-1, which had steel reinforcement, exhibited significantly fewer cracks compared with SA-S10-1, with BFRP rebars, and most of the cracks were concentrated in the central region of the slab. On the other hand, the BFRP RC slabs had extensive cracking vertically, diagonally and horizontally, as seen in the Fig. 8(d), throughout the member. The steel RC slabs had far fewer cracks, with minimal horizontal and only minor diagonal cracks, as evident in Fig. 8(c). The extensive number of vertical and diagonal cracks in the BFRP RC slabs is most likely due to the higher rate of deformation of the BFRP bars compared with the steel rebars and the differences in the bond characteristics between concrete for steel or BFRP rebars. As the load level approached the ultimate capacity of the section, horizontal cracks began to appear at the level of the reinforcement. These cracks were mainly due to the high levels of deformation of the BFRP bars and the incompatibility of the deformations between two cracks, which led to slippage between the reinforcement bars and surrounding concrete. This phenomenon has been reported in previous research also [23].

\subsection{Deflections at service load}

As stated before, it is expected that basalt FRP reinforced concrete members will undergo larger deformations compared with similar steel RC elements, due to the lower modulus of elasticity of the BFRP rebars and also the differences in bond characteristics. The level of deflection which is considered acceptable in design is dependent on a number of issues such as the importance of a given structural member, the action which is being applied (e.g. static or dynamic) and the type of structure being considered (e.g. building, frame, bridge, etc.). To satisfy the serviceability limit state (SLS) for 
deflection, different design codes for RC members typically specify a minimum thickness for the concrete element, based on the ratio of the element's effective span to its effective depth. Alternatively, deflections can be calculated and checked against the predefined limits.

\subsubsection{Design standards}

Typically, the international design codes use simplified models for the prediction of deflections of steel RC members. The models in the American ACI 440.1 R-06 [16], Canadian CSA S806-02 [17] and Russian SP295 [18] standards have been modified for reinforced concrete elements with FRP reinforcement. In Eurocode 2 [20], the deflection limit for RC members with steel reinforcement under quasi-permanent loads is the span divided by 250. This limit is employed in the current paper to ensure that the BFRP beams and slabs satisfy this deflection serviceability limit state.

The ACI 318-08 [30] design code which is for steel reinforced concrete proposes an equation for the effective second moment of inertia based on the second moment of area of the cracked and uncracked sections, as originally proposed by Branson [31]. Branson's model is applicable for steel RC member and was found to underestimate the deflections for FRP RC members [19]. Therefore, the ACI 440.1R-06 [16] code for FRP reinforced concrete includes a modification of the model for the evaluation of the effective moment of inertia of FRP RC elements, as follows:

$$
I_{e}=\left(\frac{M_{c r}}{M_{a}}\right)^{3} \beta_{d} I_{g}+\left[1-\left(\frac{M_{c r}}{M_{a}}\right)^{3}\right] I_{c r} \leq I_{g}
$$

where $\beta_{d}=\alpha_{b}\left(\frac{E_{f}}{E_{s}}+1\right)$

where $M_{c r}$ is the cracking moment calculated using Eq. $6, M_{a}$ is the moment and $E_{s}$ is the elastic modulus of steel. Eq. 15 is only valid for $M_{a} \geq M_{c r}$

In this expression, $\alpha_{\mathrm{b}}$ is a bond-dependent coefficient and based on test results for simply supported beams, the value of $\alpha_{b}$ for beams with GFRP bars is proposed to be 0.5 [32].

The cracked moment of inertia for a reinforced concrete section $\left(\mathrm{I}_{\mathrm{cr}}\right)$ is determined based on the principles of elastic analysis, and is given as:

$$
\begin{aligned}
& I_{c r}=b d^{3} k^{3} / 3+n A_{f} d^{2}(1-k)^{2} \\
& \text { where } k=\sqrt{2 \rho_{f} n+\left(\rho_{f} n\right)^{2}}-\rho_{f} n
\end{aligned}
$$

In this expression, $\mathrm{n}$ is as the modular ratio between the BFRP reinforcement and the concrete $(\mathrm{n}=$ $\left.E_{f} / E_{c}\right), b$ and $d$ are the width and effective depth of the section, respectively, and $k$ represents a factor 
employed to determine the height of the compressed area of concrete from the top surface. $A_{f}$ and $\rho_{f}$ are the total cross-sectional area of the BFRP rebars and the BFRP reinforcement ratio, respectively. The maximum deflection at the mid-span for beams under four-point and three-point bending, respectively, can be obtained from Eqs. 18 and 19, respectively:

$$
\begin{aligned}
& \delta_{\max }=\frac{P \mathrm{a}}{24 \mathrm{E}_{\mathrm{c}} \mathrm{I}_{\mathrm{e}}}\left(3 \mathrm{~L}^{2}-4 \mathrm{a}^{2}\right) \\
& \delta_{\max }=\frac{\mathrm{PL}^{3}}{48 \mathrm{E}_{\mathrm{c}} \mathrm{I}_{\mathrm{e}}}
\end{aligned}
$$

where $\mathrm{a}$ is the shear span, $\mathrm{P}$ is the service point load (as shown in the Fig. 4(a) and Fig. 5(a)), $\mathrm{L}$ is the member's effective span and $E_{c}$ is the elastic modulus of concrete which will be defined later.

The Canadian design standard CSA S806-02 [17] includes an equation for calculating the maximum deflection of FRP RC members under a number of simple load cases. This proposal is based on the assumption of a trilinear moment-curvature relationship for FRP reinforced concrete members with the slope of the three segments being $\mathrm{E}_{\mathrm{c}} \mathrm{I}_{\mathrm{g}}$, zero, and $\mathrm{E}_{\mathrm{c}} \mathrm{I}_{\mathrm{cr}}$, respectively, where $\mathrm{I}_{\mathrm{g}}$ is the gross moment of inertia of the section. If the applied bending moment is higher than the cracking moment, it is assumed that the section is fully cracked and the concrete does not contribute to the beam's capacity in the cracked regions, from tension stiffening. For beams under four-point and three-point bending and when the applied moment is more than the cracking moment, the maximum deflection can be calculated using Eqs. 20 and 21, respectively:

$$
\begin{aligned}
& \delta_{\max }=\frac{\mathrm{P} \mathrm{L}^{3}}{24 \mathrm{E}_{\mathrm{c}} \mathrm{I}_{\mathrm{cr}}}\left[3\left(\frac{\mathrm{a}}{\mathrm{L}}\right)-4\left(\frac{\mathrm{a}}{\mathrm{L}}\right)^{3}-8\left(1-\frac{\mathrm{I}_{\mathrm{cr}}}{\mathrm{I}_{\mathrm{g}}}\right)\left(\frac{\mathrm{L}_{\mathrm{g}}}{\mathrm{L}}\right)^{3}\right] \\
& \delta_{\max }=\frac{\mathrm{P} \mathrm{L}^{3}}{48 \mathrm{E}_{\mathrm{c}} \mathrm{I}_{\mathrm{cr}}}\left[1-8\left(1-\frac{\mathrm{I}_{\mathrm{cr}}}{\mathrm{I}_{\mathrm{g}}}\right)\left(\frac{\mathrm{L}_{\mathrm{g}}}{\mathrm{L}}\right)^{3}\right]
\end{aligned}
$$

In these expressions, $\mathrm{Lg}$ is the distance from the edge support to the point where the applied service moment is equal to the cracking moment, determined as:

$$
\begin{aligned}
& \mathrm{L}_{\mathrm{g}}=\mathrm{M}_{\mathrm{cr}} \mathrm{a} / \mathrm{M}_{\mathrm{a}} \text {, for four-point bending } \\
& \mathrm{L}_{\mathrm{g}}=0.5 \mathrm{M}_{\mathrm{cr}} \mathrm{L} / \mathrm{M}_{\mathrm{a}} \text { for three-point bending }
\end{aligned}
$$

where $\mathrm{M}_{\mathrm{cr}}$ and $\mathrm{M}_{\mathrm{a}}$ are the cracking moment and applied moment, respectively. 
The Russian code for FRP reinforced concrete members [18] includes a method for calculating the deflection of FRP RC beams using a reduced second moment of inertia for a concrete section with cracks and also a reduced modulus for concrete in compression, taking account of inelastic strains. For four-point bending members, $\delta_{\max }$ can be calculated from Eq. 18 by replacing $\mathrm{E}_{\mathrm{c}} \mathrm{I}_{\mathrm{e}}$ with $\mathrm{E}_{\mathrm{c}, \text { red }} \mathrm{I}_{\mathrm{cr}, \text { red }}$ and for three-point bending members, it can be calculated from Eq. 19 with replacing $\mathrm{E}_{\mathrm{c}} \mathrm{I}_{\mathrm{e}}$ with $\mathrm{E}_{c, \text { red }} \mathrm{I}_{c r, \text { red }}$. The reduced modulus for the concrete in compression is given as:

$$
\mathrm{E}_{\mathrm{c}, \mathrm{red}}=\hat{\mathrm{f}}_{\mathrm{c}} / \varepsilon_{c 1}
$$

in which $\hat{f}_{c}$ is the compressive strength of concrete and and $\varepsilon_{c 1}$ is the compressive concrete strain, taken as 0.0015 according to SP295 [18]. The reduced second moment of inertia of the section can be calculated using Eq. 16 and 17 by replacing the $\mathrm{n}$ with the term $\alpha_{f 1}=\frac{\mathrm{E}_{\mathrm{f}}}{\mathrm{E}_{\mathrm{c}, \mathrm{red}}}[18]$, where $\mathrm{E}_{\mathrm{f}}$ is elastic modulus of BFRP.

Eurocode 2 [20] proposes the expression given in Eq. 25 to obtain the maximum deflection for steel RC members. The basic principle of this equation is that members which are expected to crack, but may not be fully cracked, will behave in a manner somewhere in between uncracked and fully cracked conditions $[20]$.

$$
\delta_{\max }=(1-\xi) \delta_{1}^{\max }+\xi \delta_{2}^{\max }
$$

where:

$$
\xi=1-\beta\left(\frac{\mathrm{M}_{\mathrm{cr}}}{\mathrm{M}_{\mathrm{a}}}\right)^{\mathrm{m}}
$$

The recommended values for the $\beta$ and m coefficients are 1 and 2 , respectively. $\xi=0$ for uncracked sections.

In the above expressions $\delta_{1}^{\max }$ and $\delta_{2}^{\max }$ are calculated assuming constant uncracked and cracked sectional moments of inertia along the element. For four-point bending members, $\delta_{1}^{\max }$ and $\delta_{2}^{\max }$ can be calculated from Eq. 18 by replacing $E_{c} I_{e}$ with $E_{c} I_{g}$ and $E_{c} I_{c r}$, respectively. Similarly, for threepoint bending members, $\delta_{1}^{\max }$ and $\delta_{2}^{\max }$ can be calculated from Eq. 19 by replacing $\mathrm{E}_{\mathrm{c}} \mathrm{I}_{\mathrm{e}}$ with $\mathrm{E}_{\mathrm{c}} \mathrm{I}_{\mathrm{g}}$ and $\mathrm{E}_{\mathrm{c}} \mathrm{I}_{\mathrm{cr}}$, respectively.

All of the above expressions for the American, Canadian, European and Russian codes require determination of the elastic modulus of concrete, which can be obtained using the expressions given in Eqs. 27-30 for each code, respectively: 


$$
\begin{aligned}
& \mathrm{E}_{\mathrm{c}, \mathrm{ACI}}=4730 \sqrt{\hat{f}_{\mathrm{c}}} \\
& \mathrm{E}_{\mathrm{c}, \mathrm{CAN}}=4500 \sqrt{\hat{\mathrm{f}}_{\mathrm{c}}} \\
& \mathrm{E}_{\mathrm{c}, \mathrm{RUS}}=11.62 * \ln \hat{f}_{\mathrm{c}}-7.4713 \\
& \mathrm{E}_{\mathrm{c}, \mathrm{EC} 2}=2200\left(\frac{\hat{\mathrm{f}}_{\mathrm{c}}+8}{10}\right)^{0.3}
\end{aligned}
$$

\subsubsection{Comparison with the test results}

In this analysis, three different levels of deflection are presented, namely $\delta_{0.3}, \delta_{0.67}$ and $\delta_{\text {ult. }} \delta_{0.3}$ refers to the deflection in the member at the service moment which is taken as the moment at $30 \%$ of the ultimate moment (Mult), as adopted by other researchers (e.g. $[29,33])$. On the other hand, $\delta_{0.67}$ and $\delta_{\text {ult }}$ are the deflections at $0.67 \mathrm{M}_{\mathrm{ult}}$ and $\mathrm{Mult}_{\mathrm{ul}}$, respectively. The results are presented in Table 4. Furthermore, the table also includes comparisons between the experimental deflections and those predicted by the American $\left(\delta_{\mathrm{ACI}}\right)$, Canadian $\left(\delta_{\mathrm{CAN}}\right)$, Russian $\left(\delta_{\mathrm{RUS}}\right)$, and European $\left(\delta_{\mathrm{EC} 2}\right)$ standards at $0.3 \mathrm{Mult}$ and $0.67 \mathrm{Mult}$.

As stated before, it is expected that reinforced concrete members with BFRP reinforcement will deflect more than traditional steel reinforced concrete beams and slabs. Based on the current experimental results, the deflections at the service moment for BFRP reinforced concrete beams is around 3-4 times higher than the deflections for beams reinforced with traditional steel bars. For RC slabs, the deflections for sand-coated $10 \mathrm{~mm}$ BFRP, ribbed 10mm BFRP and ribbed $12 \mathrm{~mm}$ BFRP slab are approximately $40 \%, 25 \%$ and $40 \%$, respectively, greater than for steel RC slabs. Nevertheless, the experimental deflections at the service moment for both beams and slabs are less than the limit deflection suggested by Eurocode 2 and therefore the SLS deflection criterion is satisfied.

With reference to the predictions obtained using the American standard, as presented in Table 4, it can be seen that two different bond-dependent coefficients $\left(\alpha_{\mathrm{b}}\right)$ have been studied, namely the $\alpha_{\mathrm{b}}=$ 0.5 as recommended in the standard for GFRP RC beams and also $\alpha_{b}=0.2$. It is clear from the data in Table 4 that using the recommended value for GFRP RC elements provides a very conservative estimation of the deflections for BFRP RC beams and slabs at $0.3 \mathrm{M}_{\mathrm{ult}}$ and $0.67 \mathrm{M}_{\mathrm{ult}}$ (i.e. an underestimate the experimental deflections). The average predicted-to-experimental deflections at $0.3 \mathrm{M}_{\mathrm{ult}}$ and $0.67 \mathrm{M}_{\mathrm{ult}}$ for all members is 0.47 and 0.53 , respectively. Similarly, Zhang et al. [34] found 
that the American ACI 440.1R-06 [16] standard underestimates the deflection at $0.3 \mathrm{Mult}_{\mathrm{u}}$ and $0.67 \mathrm{Mult}_{\mathrm{ult}}$ for BFRP reinforced beams. However, when a value of 0.2 is used instead for $\alpha_{b}$, the defection predictions are in better agreement with the experimental values with average predicted-toexperimental deflections at $0.3 \mathrm{M}_{\mathrm{ult}}$ and $0.67 \mathrm{M}_{\mathrm{ult}}$ for all members of 0.78 and 0.6 , respectively. Table A.2 presents the ratio of the predicted deflection to the experimental deflection or the BFRP RC beams tested by Elgabbas et al. [23] and it is observed that using $\alpha_{\mathrm{b}}=0.2$ in the calculation provides better agreement with the test values. Therefore, it is recommended that a value of $\alpha_{b}=0.2$ is employed for the prediction of deflections for BFRP RC members, when designers are using ACI 440.1R-06 [16].

Table 4 also presents comparisons between the experimental and predicted deflections according to the Canadian CSA S806 [17], Russian SP295 [18] and European EN 1992-1-1 [20] codes at 0.3Mult and also at $0.67 \mathrm{Mult}_{\text {ult }}$ It is observed that the Canadian code overestimates the deflection in predictions for BFRP RC members at $0.3 \mathrm{M}_{\mathrm{ult}}$ and provides a better agreement at 0.67 Mult. Similarly, the Russian standard overestimates the predictions by between $30 \%$ and $61 \%$ for BFRP RC beams and $44 \%$ to $237 \%$ for BFRP RC slabs at $0.3 \mathrm{Mult}_{\text {ult }}$ with average predicted-to-experimental deflections at $0.3 \mathrm{M}_{\mathrm{ult}}$ for all members of 1.82. On the other hand, it provides better predictions for the deflections compared with the experimental data at $0.67 \mathrm{Mult}_{\mathrm{ul}}$ for BFRP RC beams and still conservative predictions for BFRP RC slabs at 0.67Mult with average S295 [18] predicted-to-experimental deflections at 0.67Mult for all members of 0.68. Furthermore, it is shown in the table that Eurocode 2 provides the most realistic predictions for the deflection of BFRP RC members at $0.3 \mathrm{Mult}_{\text {ult }}$ and $0.67 \mathrm{Mult}_{\mathrm{ult}}$, compared with the other codes of practice with average predicted-to-experimental deflections at $0.3 \mathrm{Mult}_{\mathrm{u}}$ and $0.67 \mathrm{Mult}_{\mathrm{ul}}$ for all members of 1.06 and 0.89 , respectively. For the BFRP RC beams tested by Elgabbas et al. [23], it is observed from the data given in Table A.2 that the Canadian [17] and Russian [18] standards tend to overestimate the deflections at $0.3 \mathrm{Mult}$ and $0.67 \mathrm{Mult}$ while Eurocode 2 provides more realistic deflection predictions.

Between adjacent cracks, concrete contributes in resisting tensile stresses because of the bond that develops between reinforcement and the surrounding concrete. This effect is known as tension stiffening in concrete. The deflection equation proposed in Eurocode 2 [20] inherently considers the effect of tension stiffening in concrete, resulting in the most realistic predictions for the deflection of BFRP RC members. On the other hand, the deflection expressions proposed by the CSA [17] and SP295 [18] codes assume that the section is fully cracked with no contribution from tension stiffening in the concrete in the beam's cracked regions; therefore, the deflection predictions for BFRP RC members are overestimated. The effective moment of inertia for FRP RC in the ACI standard [16] accounts for tension stiffening in the concrete by using a bond-dependent coefficient $\alpha_{\mathrm{b}}$. Adopting a 
value for $\alpha_{b}$ of 0.5 in the analysis results in an overestimation in the tension stiffening effect which leads to underestimation of the deflection while adopting a value of $\alpha_{b}=0.2$ results in deflection predictions which are in good agreement with the experimental deflections.

\subsection{Crack widths}

Figs. 9 and 10 present the load versus crack opening width for the reinforced concrete beams (i.e. SA-B10-2, R-B10-1 and R-B10-2) and one-way spanning slabs (S-S10-1, S-S10-2, SA-S6-1, SAS10-1, R-S10-1 and R-S12-1), respectively. The maximum crack width from two cracks recorded experimentally are presented in these figures. The experimental crack widths at the assumed service moment value of $0.3 \mathrm{Mult}$ are presented in Tables 5 and 6 ( $\left.\mathrm{w}_{\max , \text { Exp }}\right)$. In addition, the maximum crack widths determined using the American, Canadian, Russian and European design codes at the assumed service moment value of $0.3 \mathrm{M}_{\text {ult }}$ (i.e. $\mathrm{w}_{\max , \mathrm{ACI}}, \mathrm{w}_{\max , \mathrm{CAN}}, \mathrm{w}_{\max , \mathrm{RUS}}$ and $\mathrm{w}_{\max , \mathrm{EC} 2}$ ) are also given in the tables. The procedures for calculating these design values are described briefly hereafter.

\subsubsection{Design standards}

In the American code ACI 440.1R-06 [16], the maximum crack width of BFRP reinforced concrete flexural members (beams and slabs) can be calculated using Eq. 31:

$$
\mathrm{w}_{\text {max }, A C I}=2 \frac{\mathrm{f}_{\mathrm{f}}}{\mathrm{E}_{\mathrm{f}}} \beta \mathrm{k}_{\mathrm{b}} \sqrt{\mathrm{d}_{\mathrm{c}}{ }^{2}+\left(\frac{\mathrm{s}}{2}\right)^{2}}
$$

where:

$$
\begin{aligned}
& \beta=\frac{h-x_{e}}{d-x_{e}} \text { and } x_{e}=k d \\
& f_{f}=\frac{M_{a}}{\left(d-x_{e} / 3\right) A_{f}}
\end{aligned}
$$

In these expressions, $\mathrm{w}_{\text {max }}$ is maximum crack width given in $\mathrm{mm} ; \mathrm{f}_{\mathrm{f}}$ is the reinforcement stress at the service moment; $\beta$ is the ratio of the distance between the neutral axis and the tension face to the distance between the neutral axis and the centroid of the reinforcement; $\mathrm{x}_{\mathrm{e}}$ is the position of the neutral axis from the compression face of the concrete and is obtained from elastic analysis; $d_{c}$ is the cover thickness from the tension face to the centre of the closest reinforcing bar; $\mathrm{s}$ is the bar spacing; $\mathrm{k}$ can be calculated from Eq. 17; and $\mathrm{M}_{\mathrm{a}}$ is the service moment. The $\mathrm{kb}$ term is a coefficient that accounts for the degree of bond between the FRP bar and the surrounding concrete and the standard recommends using a value in the range between 0.6 and 1.72, depending on various conditions. 
The Canadian Highway Bridge Design Code CSA-S6-14 [15] also employ the same expression, i.e. Eq. 31, for calculating the maximum crack width, and recommend using a value of $\mathrm{k}_{\mathrm{b}}=0.8$ for the sand-coated FRP bars. On the other hand, for steel reinforced concrete beams, the maximum crack width for flexural members (i.e. beams and slabs) can be calculated using Eq. 32, in accordance with the ACI 318-03 [30] standard:

$$
\begin{aligned}
& \mathrm{W}_{\text {max }, \mathrm{ACI}}=0.011 \beta \mathrm{f}_{\mathrm{s}} \sqrt[3]{\mathrm{d}_{\mathrm{c}} \mathrm{A}_{\mathrm{o}}} * 10^{-3} \\
& \mathrm{~A}_{\mathrm{o}}=\frac{2 \mathrm{~d}_{\mathrm{c}} \mathrm{b}}{\mathrm{n}_{\mathrm{b}}}
\end{aligned}
$$

where $f_{s}$ is the stress in the steel reinforcement at service moment, $A_{o}$ is the surface area of each steer bar, and $\mathrm{n}_{\mathrm{b}}$ is the number of tension reinforcing bars. The other terms are as defined previously.

The Russian code SP295 [18] provides the expressions presented in Eqs. 33-35 for calculating the crack widths of flexural members reinforced with FRP:

$$
\mathrm{w}_{\text {max,RUS }}=\varphi_{1} \varphi_{2} \varphi_{3} \psi_{\mathrm{f}} \frac{\mathrm{f}_{\mathrm{f}}}{\mathrm{E}_{\mathrm{f}}} \mathrm{l}_{\mathrm{f}}
$$

where:

$$
\begin{aligned}
& \mathrm{l}_{\mathrm{f}}=0.25 \frac{\mathrm{bh}_{\mathrm{c}, \mathrm{t}}}{\mathrm{A}_{\mathrm{f}}} \phi \\
& \psi_{\mathrm{f}}=1-0.8 \frac{\mathrm{M}_{\mathrm{cr}}}{\mathrm{M}_{\mathrm{a}}}
\end{aligned}
$$

In these expressions, $\mathrm{f}_{\mathrm{f}}$ is the stress in the longitudinal rebars and can be calculated using Eqs. 17, $31(\mathrm{~b})$ and 31(c) and replacing the term $\mathrm{n}$ with the term $\alpha_{f 1}=\frac{\mathrm{E}_{\mathrm{f}}}{\mathrm{E}_{\mathrm{c}, \mathrm{red}}}[18] ; \phi$ is the bar diameter; $1_{\mathrm{f}}$ is the distance between adjacent normal cracks and is not less than $100 \mathrm{~mm}$ or $10 \phi$ and not greater than $200 \mathrm{~mm}$ or $20 \phi ; \psi_{\mathrm{f}}$ is a factor which accounts for the uneven distribution of strain in the reinforcing bars between cracks; $h_{c, t}$ is the height of the tension region of concrete and is taken as no less than $2 \mathrm{~d}_{\mathrm{c}}$ and no greater than $\mathrm{h} / 2$; and $\varphi_{1}, \varphi_{2}$ and $\varphi_{3}$ are factors to account for the duration of loading, the bonding between the FRP and surrounding concrete and the loading condition, respectively. $\varphi 1$ and $\varphi_{3}$ are both equal to unity for short-term loading and bending members, respectively. 
The Russian code for regular steel reinforced concrete SP 63.13330 [35] includes the same expression (i.e. Eq. 33) for calculating the maximum crack width in steel reinforced concrete flexural members, taking $\varphi_{2}$ as 0.5 for ribbed steel bars and determining $l_{\mathrm{f}}$ from:

$$
\mathrm{l}_{\mathrm{f}}=0.5 \frac{\mathrm{bh}_{\mathrm{c}, \mathrm{t}}}{\mathrm{A}_{\mathrm{f}}} \phi
$$

As stated before, Eurocode 2 does not include explicitly account for FRP reinforcement, but for steel reinforced concrete flexural members, the maximum crack is determined using the following expressions:

$$
\mathrm{w}_{\mathrm{max}, \mathrm{EC} 2}=\mathrm{s}_{\mathrm{r}, \max }\left(\varepsilon_{\mathrm{sm}}-\varepsilon_{\mathrm{cm}}\right)
$$

where:

$$
\begin{aligned}
& \mathrm{s}_{\mathrm{r}, \mathrm{max}}=3.4 \mathrm{c}+\frac{0.425 \mathrm{k}_{1} \mathrm{k}_{2} \phi}{\rho_{\mathrm{P}, \mathrm{eff}}} \leq 5(c+\phi / 2) \\
& \left(\varepsilon_{\mathrm{sm}}-\varepsilon_{\mathrm{cm}}\right)=\frac{\mathrm{f}_{\mathrm{f}}-\mathrm{k}_{\mathrm{t}} \frac{\mathrm{f}_{\mathrm{ctm}}}{\rho_{\mathrm{P}, \mathrm{eff}}}\left(1+\mathrm{n} \rho_{\mathrm{P}, \mathrm{eff}}\right)}{\mathrm{E}_{\mathrm{f}}} \geq 0.6 \frac{\mathrm{f}_{\mathrm{f}}}{\mathrm{E}_{\mathrm{f}}} \\
& \rho_{\mathrm{P}, \mathrm{eff}}=\frac{\mathrm{A}_{\mathrm{f}}}{\mathrm{b} \mathrm{h} \mathrm{h}_{\mathrm{c}, \mathrm{eff}}}
\end{aligned}
$$

and

$$
\mathrm{h}_{\mathrm{c}, \text { eff }}=\text { less of } 2.5(\mathrm{~h}-\mathrm{d}), \frac{\left(\mathrm{h}-\mathrm{x}_{\mathrm{e}}\right)}{3}, \mathrm{~h} / 2
$$

In these equations, $\mathrm{k}_{\mathrm{t}}$ is a factor that accounts for the duration of loading ( $\mathrm{k}_{\mathrm{t}}=0.6$ for short-term load); $\mathrm{s}_{\mathrm{r}, \max }$ is the maximum crack spacing; $\mathrm{c}$ is the concrete cover; $\mathrm{k}_{2}$ is a coefficient accounting for the nature of the strain distribution which for cracking due to flexure can be taken as 0.5 ; $\mathrm{h}_{\mathrm{c}, \mathrm{eff}}$ is the depth of the effective tension area of concrete; $f_{c t m}$ is the tensile strength of concrete; $\rho_{P, e f f}$ is the effective reinforcement ratio; and $\mathrm{k}_{1}$ is a coefficient accounting for the bond properties of the bar. Therefore, to account for different types of reinforcement, including BFRP, it is the $\mathrm{k}_{1}$ term which needs to be calibrated. 


\subsubsection{Comparison with the beam test results}

As stated previously, the crack widths are measured taken about every $5 \mathrm{kN}$ of the applied load for the beams and every $1 \mathrm{kN}$ for the slabs. It is important to highlight there is inevitably a degree of randomness and unpredictability about the development of cracks in concrete, and the degree to which they open, as this behaviour is governed by many inter-related factors which are not always quantifiable (e.g. level of bond that develops, degree of micro-cracking within the specimens, position of the crack relative to the rebars, etc.). Therefore, the following discussions and comparisons are included to highlight some behavioural observations rather than drawing specific conclusions.

With this in mind, Fig. 9 presents the crack widths that developed with increasing levels of load for three of the beam specimens. The data from the first two tests is not available as the technique for measuring the cracks was still being verified during these experiments. It is noteworthy that all of the beams examined in the current programme have the same reinforcement ratio. It is shown in the figure that all of the beams developed cracks with very similar width until around $30 \mathrm{kN}$ of applied load. Thereafter, beams R-B10-1 exhibited slightly greater crack widths compared with SA-B10-2 and RB10-2, although it is difficult to draw any conclusive analysis of this owing to the somewhat random nature of crack development. The development of cracks, and the widths to which they open, is intrinsically linked to the bond stresses that develop between the reinforcement and the surrounding concrete, and can be very sensitive to any localised micro-cracking that develops.

Table 5 presents a comparison between the experimental crack widths with those obtained theoretically using ACI 440 [16], with a bonding coefficient $\left(\mathrm{k}_{\mathrm{b}}\right)$ equal to 0.6, 0.8, 1.0 and 1.72, respectively. It is clear that when the bond coefficient is 0.6 , the ACI code underestimates the crack width at the service moment $(0.3 \mathrm{Mult})$ for beams by between 37 and $48 \%$. When $\mathrm{kb}$ is increased to 0.8 (as also proposed by the Canadian Highway Bridge Design Code), the predicted crack widths are underestimates by around 16 to 31\%. Similarly, Abed and Alhafiz [29] and Elgabbas et al. [23] observed that using $\mathrm{kb}_{\mathrm{b}}=0.8$ resulted in an underestimation of the crack width. On the other hand, when $\mathrm{kb}$ is given a value of 1.72 which is the maximum provided in the code, the crack widths are overestimated by between $49 \%$ and $80 \%$. The ACI code procedure for determination of the crack widths provides the most acceptable predictions for the current test data when $\mathrm{k}_{\mathrm{b}}$ is taken as 1.0, resulting in a $4 \%$ overestimation of the opening size for beams SA-B10-2 and R-B10-1 and a 12\% underestimation for the beam R-B10-2.

Table 6 presents comparisons between the experimental and predicted crack widths using the Russian FRP design code [18], as presented in Eq. 33. Two different values of bond coefficient $(\varphi 2)$ are employed namely 0.7 and 0.5 , which $\varphi_{2}=0.7$ is suggested by Russian code. It is observed that when 
a bonding factor of 0.7 is used, the crack widths are overestimated by between 15 and 39\%. On the other hand, when $\varphi_{2}$ is taken as 0.5 , the Russian code provides more accurate predictions, generally quite close to the experimental readings and on the conservative side. It is noted that for R-B10-2, this approach provides a $17 \%$ underestimate of the crack width, but it appears that the behaviour for this test beam may have been unusual owing to unpredictable experimental factors. Table 6 also includes the Eurocode 2 crack width predictions, assuming a bond coefficient $\left(\mathrm{k}_{1}\right)$ of 0.8 . It can be shown that the European approach provides accurate predictions for the beams SA-B10-2 and R-B101 and underestimates the crack width for the beam R-B10-2, again by $17 \%$, similar to the Russian code.

\subsubsection{Comparison with the slab test results}

Fig. 10 presents the average crack widths that develop for the one-way spanning reinforced concrete slabs in this experimental programme. It is observed that the crack opening width for the steel reinforced concrete slabs was significantly lower than for the sand-coated and ribbed BFRP reinforced concrete slabs for the duration of the tests. Furthermore, it is noted that as the reinforcement ratio of the basalt FRP slabs increased (e.g. the diameter of the used BFRP bar increased), the crack widths reduced. Tables 5 and 6 include the crack width values predicted by the international design codes (American in Table 5 and Russian and European in Table 6). It is shown that the American ACI 440 [16] standard consistently overestimates the crack width size for all considered kb values (ranging from 0.6 to 1.72 ). When $\mathrm{kb}$ is taken as 0.6 , the overestimation is between $63 \%$ and $134 \%$ higher than the corresponding experimental value, while these overestimates increase to between $157 \%$ and $212 \%$ of the experimental results when $\mathrm{kb}$ is assumed to be 0.8 (which is also the recommended value given in the Canadian code). Finally, when $\mathrm{k}_{b}$ is given a value of 1.72 , the American codes overestimates the crack width by $159 \%$ and $571 \%$ higher than Wmax,Exp at the service moment.

With reference to the data presented in Table 6, it is observed that the Russian SP295 [18] design code overestimates the experimental crack width at $0.3 \mathrm{Mult}_{\text {ult }}$ by $60 \%, 42 \%$ and $38 \%$ for the slabs SAS6-1, SA-S10-1 and R-S10-1, respectively, when the bonding factor $\left(\varphi_{2}\right)$ is given a value of 0.7. On the other hand, for the same scenario, the standard underestimates the crack width for R-S12-1 by $10 \%$. However, when $\varphi_{2}$ is given a value of 0.5 , the Russian code provides a more accurate assessment of the crack opening size (a 14\% overestimation for the slab SA-S6-1, accurate predictions for the slabs SA-S10-1 and R-S10-1, and 35\% underestimation for the slab R-S12-1). Furthermore, the Eurocode 2 crack width predictions are shown to be relatively accurate for the slab R-S12-1 but 
overestimates the crack width by $17 \%, 41 \%$ and $25 \%$ for the slabs SA-S6-1, SA-S10-1 and R-S10-1, respectively.

In conclusion to this section on cracking and crack widths, it is clear that the results both from the experiments and also the comparison with design codes indicate that the development and propagation of cracks and the size of crack widths is extremely difficult to analyse and predict either qualitatively or quantitatively, with a high degree of accuracy. Whilst some trends have clearly been identified, nevertheless, it would be necessary to conduct a significant number of specific tests to develop a full understanding of the cracking behaviour. Even then, it is inevitable that the way in which cracks develop has a degree of unpredictability, which makes this property very difficult to codify. This is an area clearly requiring more detailed analysis and research in order to develop design standards which are at least on the safe side.

\section{Conclusions}

This paper has presented a detailed description and analysis of a series of experiments on reinforced concrete beams and slabs that are reinforced with novel basalt FRP rebars. For comparison, the experimental programme also included similar specimens reinforced with carbon steel bars. The tests have generally shown that the members with BFRP bars perform very well, and provide a valid and durable alternative to traditional carbon steel reinforced concrete. In the analysis of the test results presented herein, particular attention was given to the overall load-deflection relationship as well as the cracking moment, bending moment capacity, deflections and the crack opening width at service loading. These values were compared with four international design standards including three that currently exist for FRP reinforced concrete beams (the American, Canadian and Russian codes) as well as Eurocode 2, which currently only contains guidance for the design of carbon steel reinforced concrete elements. Based on the test results and discussion presented herein, the following conclusions have been reached:

1. The accuracy of the cracking moment predictions depends on the type of element (beam or slab), reinforcement type (steel or BFRP) and BFRP type (sand-coated or ribbed). The American, Canadian and European codes overestimate the cracking moment whereas the Russian code underestimate the cracking moment in most cases. It is interesting to note that all of the codes are generally more unconservative for the beam cracking moment predictions compared with the slab cracking moments.

2. The experimental moment capacity of the BFRP RC beams was higher than that of the steel RC beams with the same reinforcement ratio while for RC slab members, it is interesting to note that the steel RC slabs exhibited higher moment capacity than the BFRP 
RC slabs by about 24\%. Furthermore, the American and Canadian codes provide acceptable predictions of the flexural capacity of BFRP RC beams while Eurocode 2 slightly overestimates the bending moment capacity and the Russian standard overestimates the moment capacity by an average of $16.5 \%$. Furthermore, the American, Canadian and European codes provide acceptable predictions for the flexural capacity of one-way slabs while the Russian standard provides the most accurate flexural capacity predictions.

3. The crack patterns that developed in both the steel and BFRP RC beams were similar. However, the cracks that developed in BFRP RC beams were longer in length than those for the steel RC beams at the same loading level. The steel RC slabs exhibited significantly fewer cracks compared with the BFRP RC slabs, and most of the cracks were concentrated in the central region of the slab in which the BFRP RC slabs had extensive cracking vertically, diagonally and horizontally at the level of the reinforcement and the steel RC slabs had minimal horizontal and only minor diagonal cracks. Since the reinforcement ratios of all BFRP RC beams and slabs were higher than the balanced reinforcement ratio, at the ultimate load, the BFRP RC beams and slabs failed by concrete crushing whereas the steel RC beams and slabs fails by steel yielding.

4. Based on the results presented, the recommended value for the bond-dependent coefficient $\alpha_{\mathrm{b}}$ is 0.2 for calculating deflections of BFRP RC members at the service moment, in accordance with the design equations given in ACI 440.1R-06. It is observed that the Canadian and Russian standards overestimate the deflection in predictions for BFRP RC members at the service moment. Furthermore, Eurocode 2 provides the most realistic predictions for the deflection of BFRP RC members at the service moment, compared with the other codes of practice examined.

5. It is recommended that bonding coefficients $(\mathrm{kb})$ between 0.8 and 1.0 are used to calculate the crack opening width in accordance with ACI 440.1R-06. The code provides the most accurate predictions for the crack opening width of RC BFRP beams at the service moment while it overestimates the crack widths for RC BFRP slabs compared to the experimental values. It is recommended that a bonding factor $\left(\varphi_{2}\right)$ of 0.5 is used to calculate crack widths when applying the Russian code SP295, and this provides accurate and generally conservative predictions. Finally, assuming a bond coefficient $\left(\mathrm{k}_{1}\right)$ of 0.8 in for calculation the crack opening widths in accordance with Eurocode 2 provides accurate predictions for most BFRP RC beams but this standard generally overestimates the crack width for RC slabs. 


\section{Acknowledgements}

The authors would like to thank Access to Innovation A2I, a match funded project between London South Bank University and ERDF, for funding the tests. Furthermore, they would also like to thank the technicians Graham Bird and Paul Elsdon for their continuous support in the Laboratory and also acknowledge the assistance of the undergraduate students Beniamin Romanet and Jack Hendy during testing.

\section{References}

[1] Apostolopoulos, C.A. and Papadakis, V.G., 2008. Consequences of steel corrosion on the ductility properties of reinforcement bar. Construct Build Mater, 22(12), pp.2316-2324.

[2] Ožbolt, J., Balabanić, G. and Kušter, M., 2011. 3D Numerical modelling of steel corrosion in concrete structures. Corros Sci, 53(12), pp.4166-4177.

[3] Apostolopoulos, C.A. and Papadakis, V.G., 2008. Consequences of steel corrosion on the ductility properties of reinforcement bar. Construct Build Mater, 22(12), pp.2316-2324.

[4] Broomfield, J.P., 2006. Corrosion of steel in concrete: understanding, investigation and repair. CRC Press.

[5] Bashtannik, P.I., Kabak, A.I. and Yakovchuk, Y.Y., 2003. The effect of adhesion interaction on the mechanical properties of thermoplastic basalt plastics. Mech of Compos Mater, 39(1), pp.85-88.

[6] Fiore, V., Scalici, T., Di Bella, G. and Valenza, A., 2015. A review on basalt fibre and its composites. Compos Part B-Eng, 74, pp.74-94.

[7] Wei, B., Cao, H. and Song, S., 2011. Degradation of basalt fibre and glass fibre/epoxy resin composites in seawater. Corros Sci, 53(1), pp.426-431.

[8] Inman, M., Thorhallsson, E.R. and Azrague, K., 2017. A mechanical and environmental assessment and comparison of basalt fibre reinforced polymer (BFRP) rebar and steel rebar in concrete beams. Energy Proced, 111, pp.31-40.

[9] Alam, M.S. and Hussein, A., 2011. Experimental investigation on the effect of longitudinal reinforcement on shear strength of fibre reinforced polymer reinforced concrete beams. Can J Civil Eng, 38(3), pp.243-251. 
[10] Ashour, A.F., 2005. Shear Performance of Concrete Beams Reinforced with CFRP Bars. In Proceedings of the Tenth International Conference on Civil, Structural and Environmental Engineering Computing (p. 105). Civil-Comp Press.

[11] Abdul-Salam, B., Farghaly, A.S. and Benmokrane, B., 2016. Mechanisms of shear resistance of one-way concrete slabs reinforced with FRP bars. Construct Build Maters, 127, pp.959-970.

[12] Mahroug, M.E., Ashour, A.F. and Lam, D., 2014. Experimental response and code modelling of continuous concrete slabs reinforced with BFRP bars. Compos Struct, 107, pp.664-674.

[13] Urbanski, M., Lapko, A. and Garbacz, A., 2013. Investigation on concrete beams reinforced with basalt rebars as an effective alternative of conventional R/C structures. Proced Eng, 57, pp.11831191.

[14] Duic, J., Kenno, S. and Das, S., 2018. Performance of concrete beams reinforced with basalt fibre composite rebar. Construct Build Mater, 176, pp.470-481.

[15] Canadian Standards Association, 2014. Canadian highway bridge design code (CAN/CSA-S614) Ontario, Canada.

[16] American Concrete Institute. Committee 440, 2006. Guide for the Design and Construction of Concrete Reinforced with FRP Bars: ACI 440.1 R-06. Farmington Hills: American Concrete Institute.

[17] Canadian Standards Association, 2012. Design and Construction of Building Structures with Fibre-Reinforced Polymers,(CAN/CSA S806-02). Canadian Standards Association Mississauga, Ont.

[18] SP 295.1325800.2017 (Russian State Standard), Konstrukcii betonnye, armirovannye polimernoj kompozitnoj armaturoj. Pravila proektirovaniya. Obshchiye Tekhnicheskiye Usloviya [Concrete structures reinforced with fibre-reinforced polymer bars. Design rules], Standartinform [Publisher], Moscow, 2017 (in Russian)

[19] fib (Fédération Internationale du Béton), 2007. fib - TG 9.3: Technical Report: FRP Reinforcement in RC Structures. fib, Lausanne, Switzerland.

[20] EN 1992-1-1 (2004) Eurocode 2: Design of concrete structures, European Committee for Standardization.

[21] Mousa, S., Mohamed, H.M., Benmokrane, B. and Ferrier, E., 2018. Flexural behavior of fullscale circular concrete members reinforced with basalt FRP bars and spirals: Tests and theoretical studies. Compos Struct, 203, pp.217-232. 
[22] Pawłowski, D. and Szumigała, M., 2015. Flexural behaviour of full-scale basalt FRP RC beamsexperimental and numerical studies. Proced Eng, 108, pp.518-525.

[23] Elgabbas, F., Vincent, P., Ahmed, E.A. and Benmokrane, B., 2016. Experimental testing of basalt-fiber-reinforced polymer bars in concrete beams. Compos Part B-Eng, 91, pp.205-218.

[24] Zhang, L., Sun, Y. and Xiong, W., 2015. Experimental study on the flexural deflections of concrete beam reinforced with Basalt FRP bars. Mater Struct, 48(10), pp.3279-3293.

[25] Feng, J., Zhou, Y., Wang, P., Wang, B., Zhou, J., Chen, H., Fan, H. and Jin, F., 2017. Experimental research on blast-resistance of one-way concrete slabs reinforced by BFRP bars under close-in explosion. Eng Struct, 150, pp.550-561.

[26] Pilakoutas, K., Neocleous, K. and Guadagnini, M., 2002. Design philosophy issues of fiber reinfored polymer reinforced concrete structures. J Compos Construct, 6(3), pp.154-161.

[27] Gul, M., 2016. Effect of cube size on the compressive strength of concrete. Int. J. Eng. Dev. Res, 4, pp.956-959.

[28] Feeser, W.K. and Brown, V.L., 2005. Guide examples for design of concrete reinforced with FRP bars. Sp Pub, 230, pp.935-954.

[29] Abed, F. and Alhafiz, A.R., 2019. Effect of basalt fibers on the flexural behavior of concrete beams reinforced with BFRP bars. Compos Struct, 215, pp.

[30] American Concrete Institute. Committee 318, 2008. Building Code Requirements for Reinforced Concrete: ACI 318-08. American Concrete Institute.

[31] Branson, D. E., 1977. Deformation of Concrete Structures, McGraw-Hill, New York, 537.

[32] American Concrete Institute. Committee 440, 2003. Guide for the Design and Construction of Concrete Reinforced with FRP Bars: ACI 440.1 R-03. Farmington Hills: American Concrete Institute.

23-34.

[33] El-Nemr, A., Ahmed, E.A. and Benmokrane, B., 2013. Flexural Behavior and Serviceability of Normal-and High-Strength Concrete Beams Reinforced with Glass Fiber-Reinforced Polymer Bars. ACI Struct J, 110(6).

[34] Zhang, L., Sun, Y. and Xiong, W., 2015. Experimental study on the flexural deflections of concrete beam reinforced with Basalt FRP bars. Mater Struct, 48(10), pp.3279-3293.

[35] SP 63.13330.2012 Concrete and reinforced concrete. Design code (Moscow) p 156 


\section{Figures Captions}

Fig.1: Basalt FRP samples including (a) a sand-coated bar and (b) a ribbed bar

Fig.2: Typical stress-strain relationship of steel and BFRP bar

Fig. 3: beam concrete casting

Fig. 4: Schematic views of the beam specimen configuration including (a) elevation view and end view; (b) the beam moulds showing the reinforcement arrangements.

Fig. 5: Slab test specimens including (a) schematic of the slab specimens in elevation and end-view, and (b) the slab moulds showing the reinforcement arrangements

Fig. 6: Load-deflection relationship for beam specimens

Fig. 7: Load-deflection relationship for one-way slab specimens

Fig. 8: Crack patterns and propagation for the beams (a) S-B10-1; (b) R-B10-1, and for the slabs (c) S-S10-1; (d) SA-S10-1.

Fig. 9: Development of crack openings with increasing applied loads for BFRP RC beams 


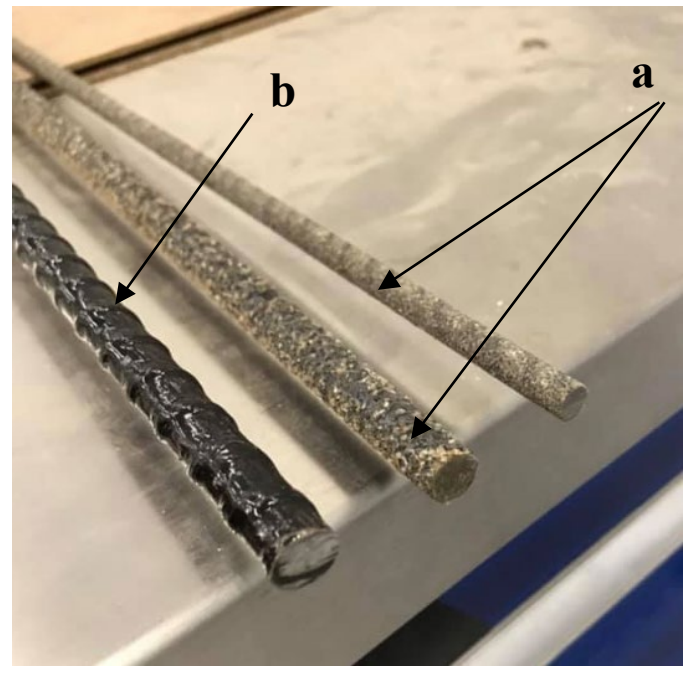

Fig.1: Basalt FRP samples including (a) a sand-coated bar and (b) a ribbed bar 


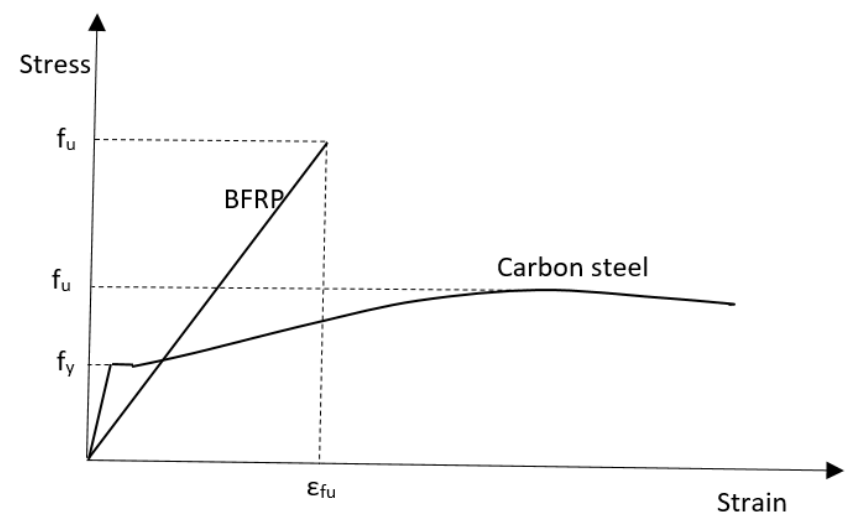

Fig.2: Typical stress-strain relationship of carbon steel and BFRP bars 


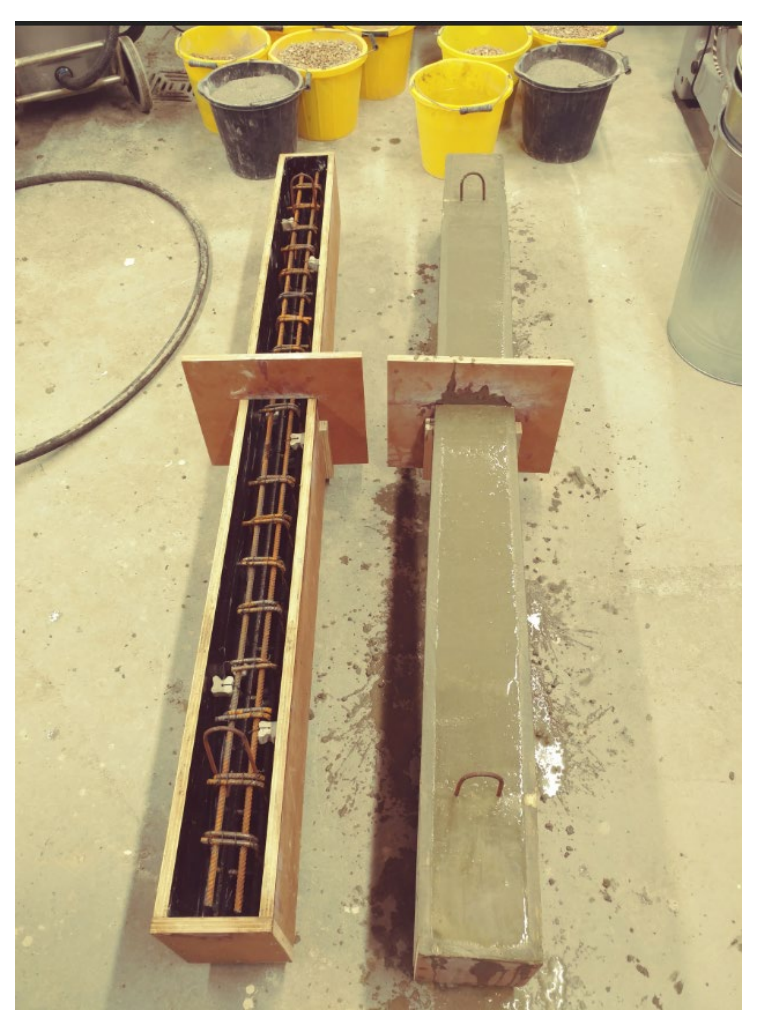

Fig. 3: Beam concrete casting 


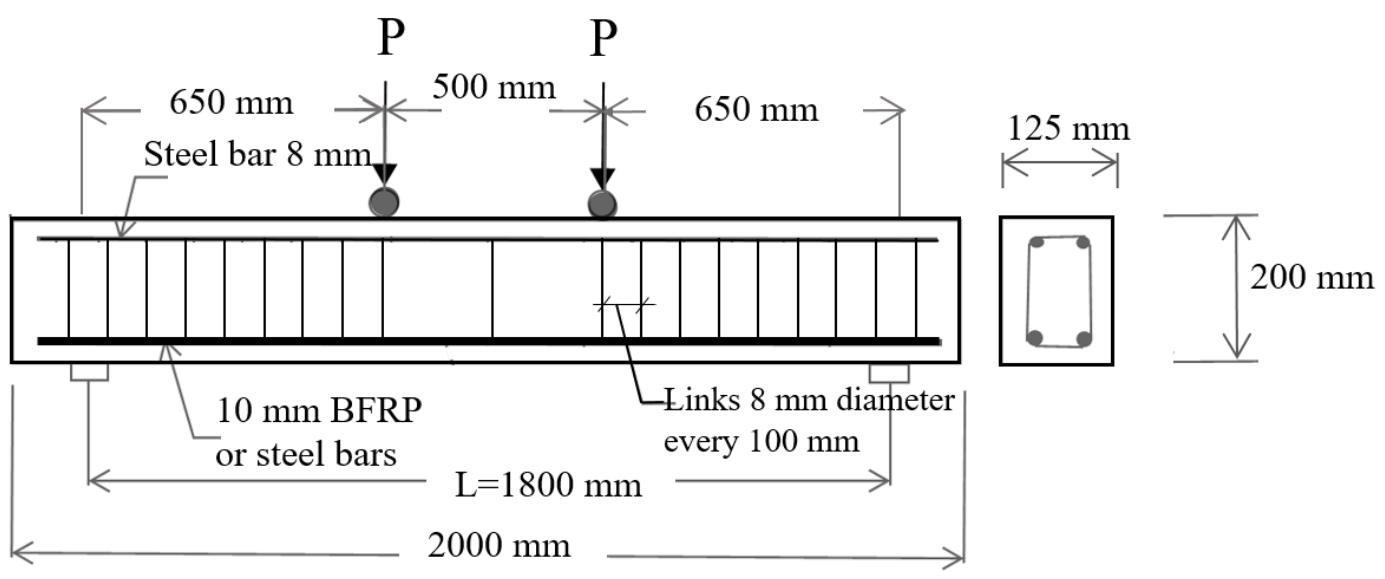

(a)

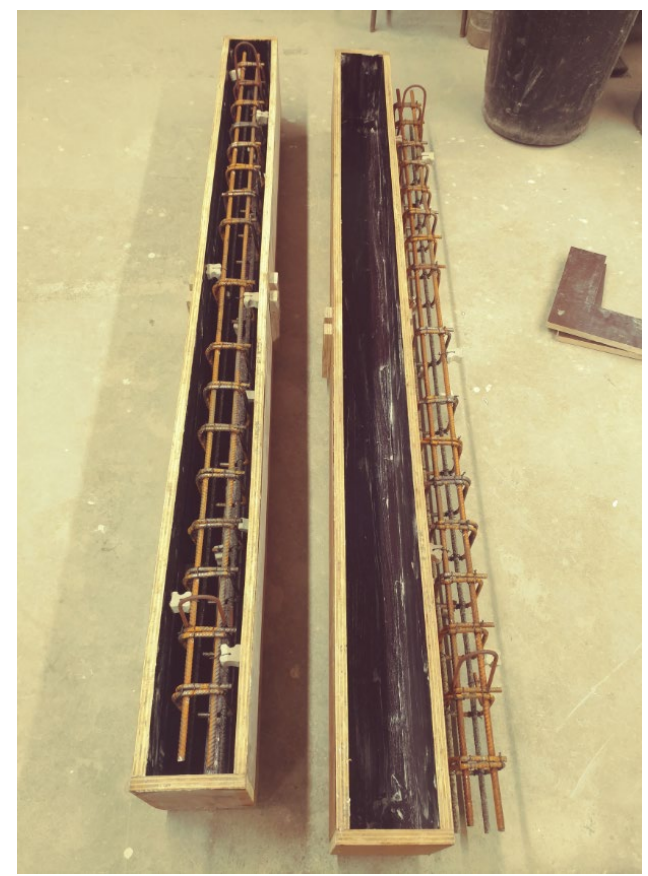

(b)

Fig. 4: Schematic views of the beam specimen configuration including (a) an elevation and end view and (b) the beam moulds showing the reinforcement arrangements. 


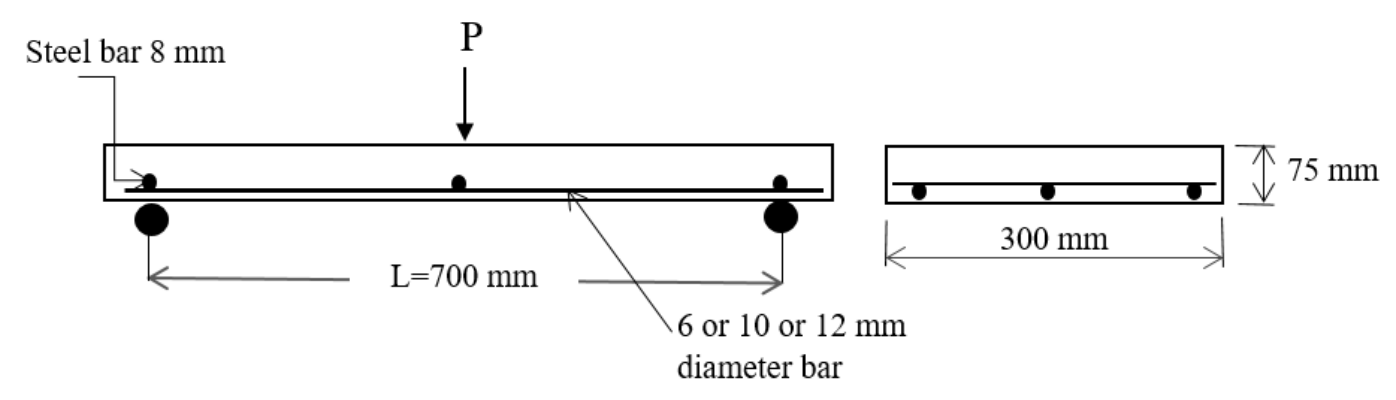

(a)

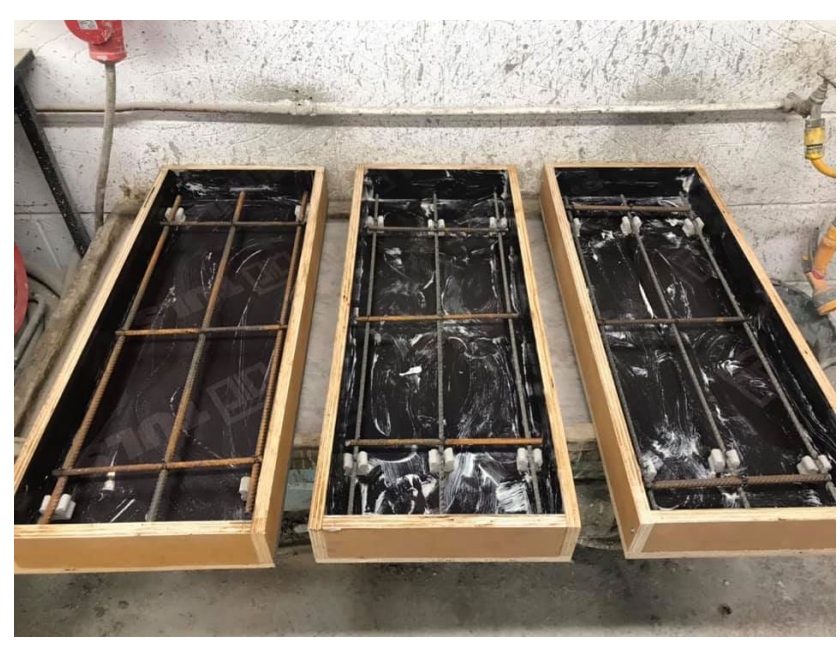

(b)

Fig. 5: Slab test specimens including (a) a schematic of the slab specimens in elevation and end-view, and (b) the slab moulds showing the reinforcement arrangements 


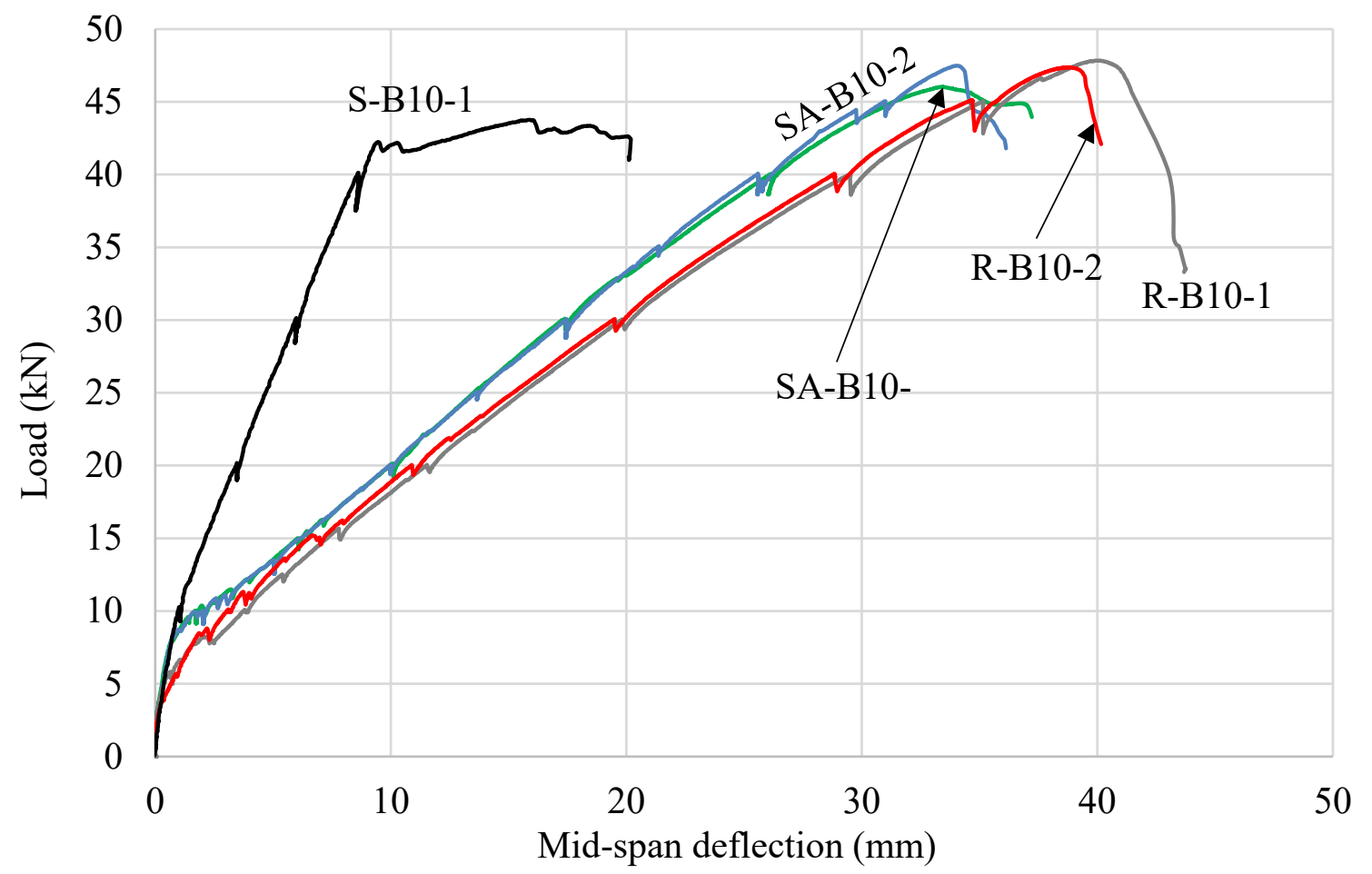

Fig. 6: Load-deflection relationships for the beam specimens 


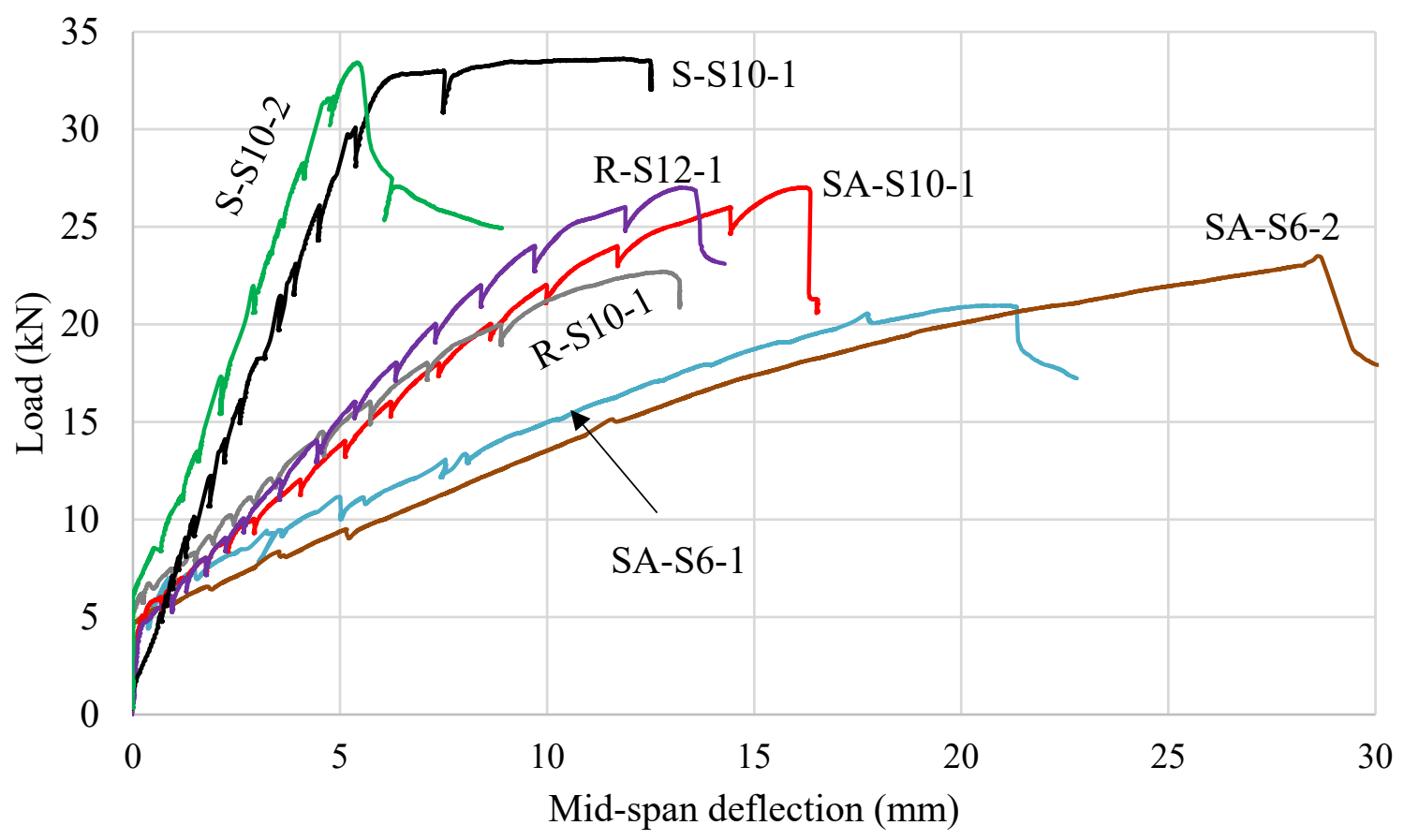

Fig. 7: Load-deflection relationships for the one-way slab specimens 


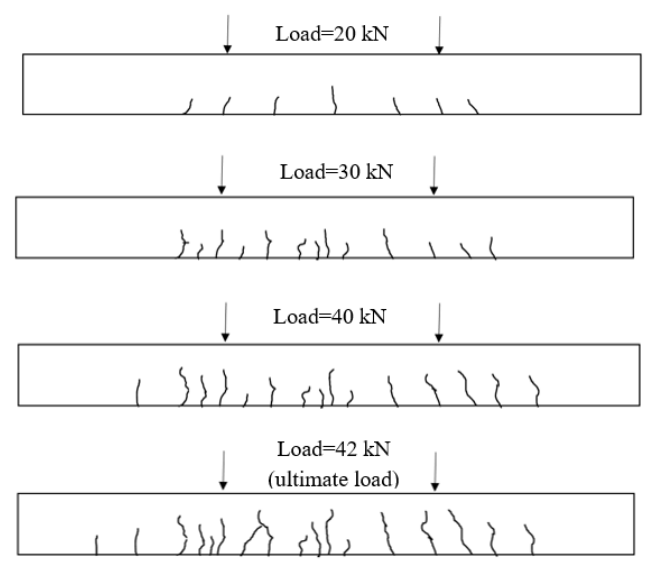

(a)
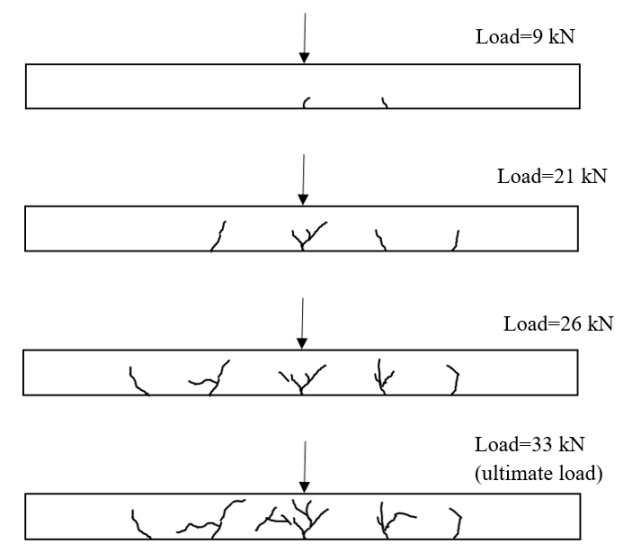

(c)
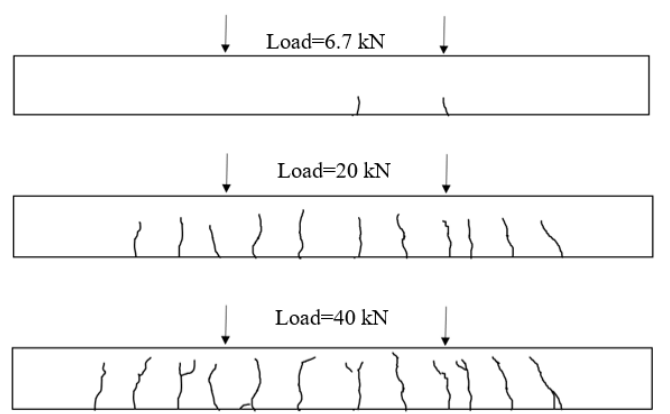

Load $=47.8 \mathrm{kN}$

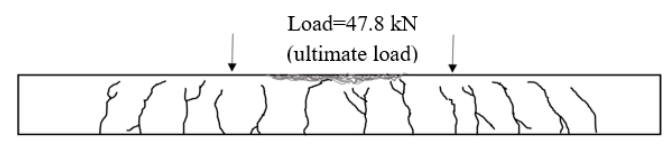

(b)
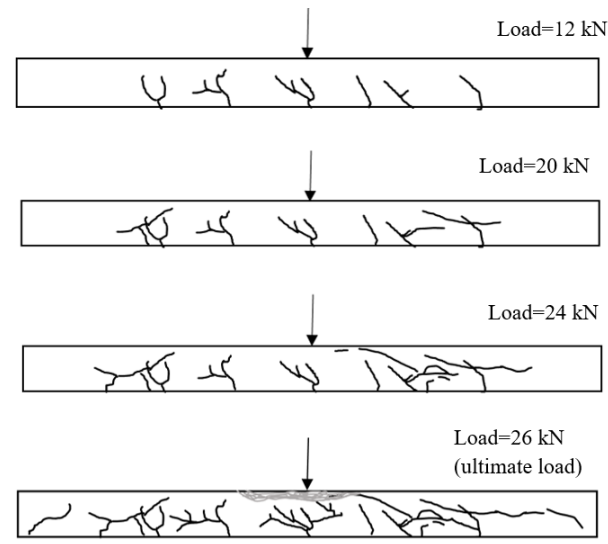

(d)

Fig. 8: Crack patterns and propagation for the beams (a) S-B10-1 and (b) R-B10-1, and for the slabs (c) S-S10-1 and (d) SA-S10-1. 


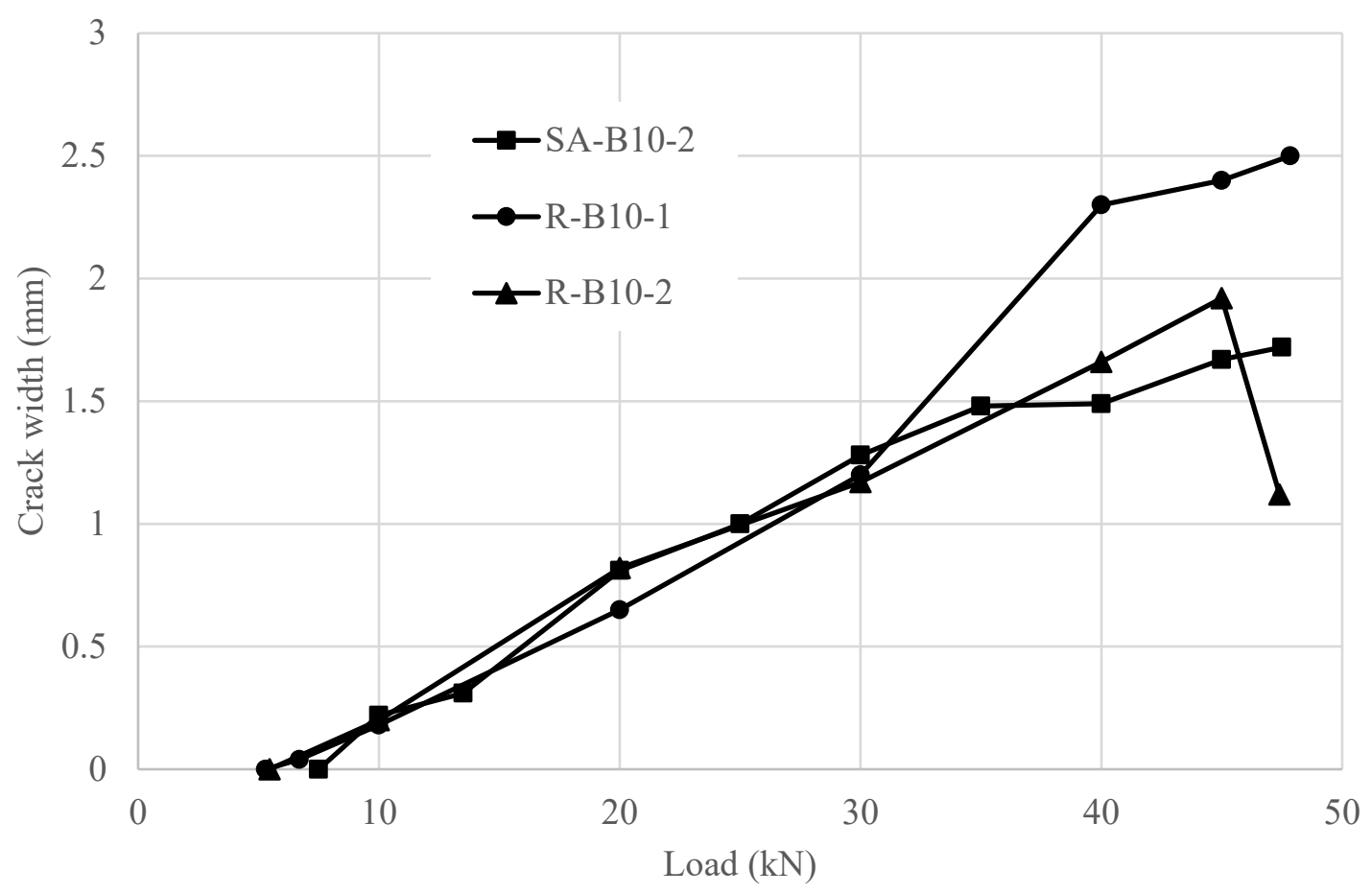

Fig. 9: Development of crack openings with increasing applied loads for BFRP RC beams 


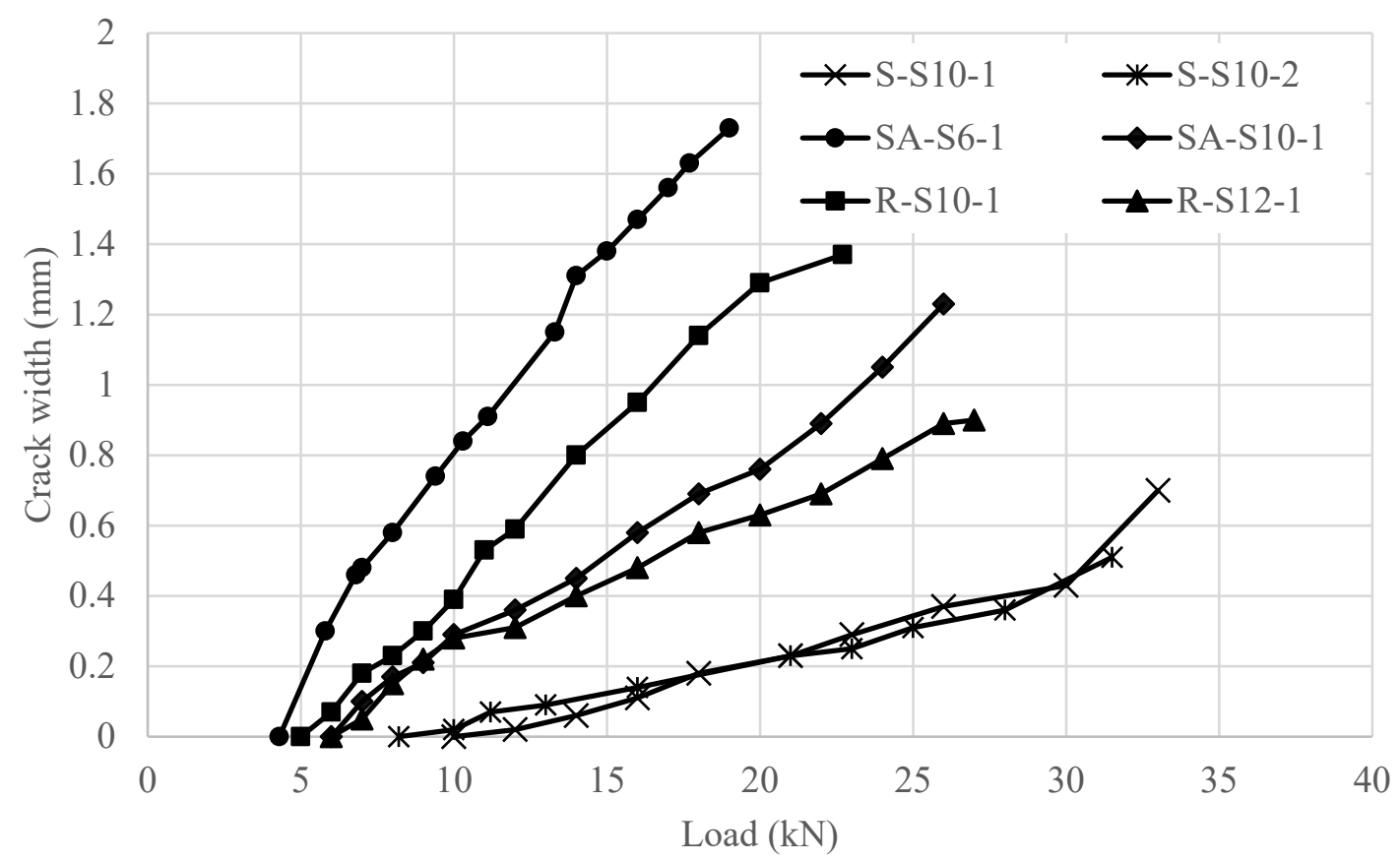

Fig. 10: Development of crack openings with increasing applied loads for one-way spanning BFRP RC slabs 


\section{List of Tables}

Table 1: Mechanical properties of BFRP and steel bars

Table 2: Concrete strength values for the test specimens and balanced reinforcement ratio values

Table 3: Experimental and theoretical cracking and ultimate moment values for the test specimens

Table 4: Predicted-to-experimental deflection of BFRP RC members according to various international design codes

Table 5: Comparison of the experimental crack widths for BFRP RC members with the American design codes

Table 6: Comparison of the experimental crack widths for BFRP RC members with the Russian and European design codes

Table A.1: Experimental and theoretical cracking and ultimate moment values for the test beams by Elgabbas et al. [23]

Table A.2: Predicted-to-experimental deflection of BFRP RC beams tested by Elgabbas et al. [23] according to various international design codes 
Table 1: Mechanical properties of BFRP and steel bars

\begin{tabular}{|l|c|c|c|c|}
\hline Type of bar & $\begin{array}{c}\text { Diameter } \\
(\mathbf{m m})\end{array}$ & $\begin{array}{c}\mathbf{f}_{\mathbf{y}} \\
(\mathbf{M P a})\end{array}$ & $\begin{array}{c}\mathbf{f}_{\mathbf{u}} \\
(\mathbf{M P a})\end{array}$ & $\begin{array}{c}\mathbf{E} \\
(\mathbf{G P a})\end{array}$ \\
\hline $\begin{array}{l}\text { Sand-coated } \\
\text { basalt FRP }\end{array}$ & 6 & N/A & 1452 & 55 \\
\cline { 2 - 5 } Ribbed basalt & 10 & N/A & 1565 & 56 \\
\cline { 2 - 5 } FRP & 10 & N/A & 1356 & 54 \\
\hline Steel & 12 & N/A & 1356 & 54 \\
\hline
\end{tabular}


Table 2: Concrete strength values for the test specimens and balanced reinforcement ratio values

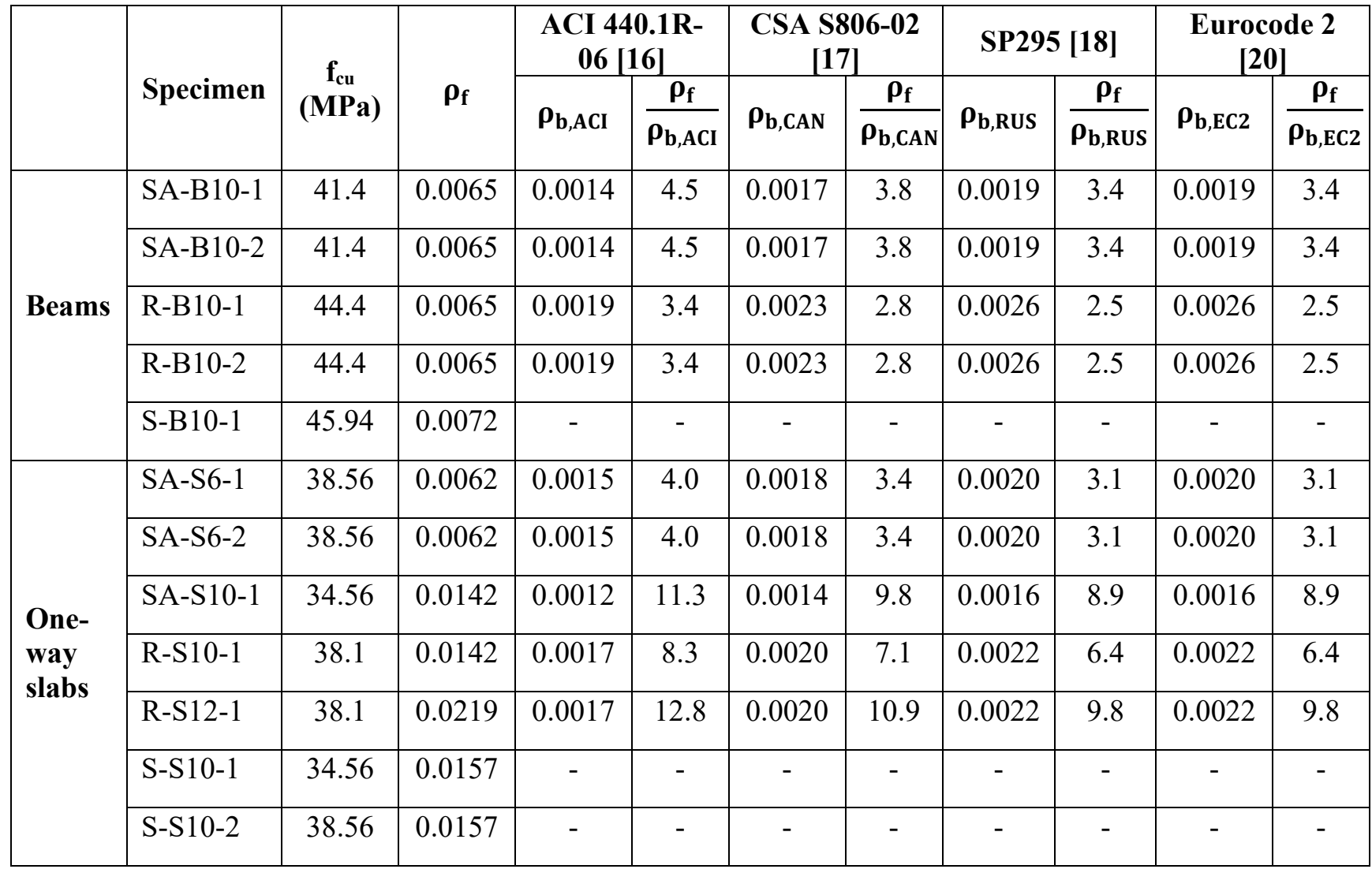


Table 3: Experimental and theoretical cracking and ultimate moment values for the test specimens

\begin{tabular}{|c|c|c|c|c|c|c|c|c|c|c|}
\hline \multirow{2}{*}{ Specimen } & \multicolumn{2}{|c|}{$\begin{array}{l}\text { Experiment } \\
(\mathrm{kNm})\end{array}$} & \multicolumn{2}{|c|}{$\begin{array}{c}\text { ACI 440.1R-06 } \\
{[16]}\end{array}$} & \multicolumn{2}{|c|}{$\begin{array}{c}\text { CSA S806-02 } \\
{[17]}\end{array}$} & \multicolumn{2}{|c|}{$\begin{array}{c}\text { SP295 } \\
{[18]}\end{array}$} & \multicolumn{2}{|c|}{$\begin{array}{c}\text { Eurocode } 2 \\
{[20]}\end{array}$} \\
\hline & $\mathbf{M}_{\mathrm{cr}, \mathrm{Exp}}$ & $\mathbf{M}_{\text {ult,Exp }}$ & $\frac{M_{\text {cr,ACI }}}{M_{c r, \operatorname{Exp}}}$ & $\frac{\mathrm{M}_{\mathrm{ult}, \mathrm{ACI}}}{\mathrm{M}_{\mathrm{ult}, \mathrm{Exp}}}$ & $\frac{M_{\text {cr,CAN }}}{M_{\text {cr,Exp }}}$ & $\frac{M_{\text {ult,CAN }}}{M_{\text {ult,Exp }}}$ & $\frac{\mathrm{M}_{\mathrm{cr}, \mathrm{RUS}}}{\mathrm{M}_{\mathrm{cr}, \mathrm{Exp}}}$ & $\frac{M_{\text {ult,RUS }}}{M_{\text {ult,Exp }}}$ & $\frac{M_{\text {cr,EC2 }}}{M_{\text {cr,Exp }}}$ & $\frac{\mathrm{M}_{\mathrm{ult}, \mathrm{EC} 2}}{\mathrm{M}_{\mathrm{ult}, \mathrm{Exp}}}$ \\
\hline SA-B10-1 & 2.60 & 14.95 & 1.15 & 1.01 & 1.11 & 1.06 & 0.85 & 1.18 & 1.01 & 1.05 \\
\hline SA-B10-2 & 2.44 & 15.43 & 1.23 & 0.98 & 1.19 & 1.03 & 0.91 & 1.14 & 1.08 & 1.04 \\
\hline R-B10-1 & 1.72 & 15.54 & 1.8 & 0.99 & 1.74 & 1.04 & 1.35 & 1.17 & 1.58 & 1.06 \\
\hline R-B10-2 & 1.77 & 15.50 & 1.75 & 0.99 & 1.69 & 1.05 & 1.31 & 1.17 & 1.55 & 1.06 \\
\hline S-B10-1 & 3.25 & 13.65 & 0.97 & - & 0.94 & - & 0.73 & - & 0.92 & 0.96 \\
\hline SA-S6-1 & 0.75 & 3.68 & 1.30 & 0.72 & 1.25 & 0.76 & 0.95 & 0.84 & 1.11 & 0.76 \\
\hline SA-S6-2 & NA & 4.15 & NA & 0.56 & NA & 0.59 & NA & 0.74 & NA & 0.67 \\
\hline SA-S10-1 & 1.05 & 4.73 & 0.88 & 0.68 & 0.85 & 0.71 & 0.63 & 0.78 & 0.74 & 0.70 \\
\hline R-S10-1 & 0.88 & 3.97 & 1.11 & 0.84 & 1.07 & 0.88 & 0.81 & 0.97 & 0.95 & 0.88 \\
\hline R-S12-1 & 1.05 & 4.73 & 0.92 & 0.79 & 0.89 & 0.82 & 0.67 & 0.92 & 0.80 & 0.82 \\
\hline S-S10-1 & 1.58 & 5.88 & 0.59 & - & 0.57 & - & 0.42 & - & 0.51 & 0.8 \\
\hline S-S10-2 & 1.44 & 5.83 & 0.68 & - & 0.66 & - & 0.50 & - & 0.60 & 0.82 \\
\hline \multicolumn{3}{|l|}{ Average } & 1.13 & 0.84 & 1.09 & 0.88 & 0.8 & 0.99 & 0.98 & 0.89 \\
\hline \multicolumn{3}{|c|}{ Coefficient of variation (\%) } & 34.4 & 19.5 & 34.34 & 19.64 & 35.64 & 18.13 & 34.7 & 16.33 \\
\hline
\end{tabular}


Table 4: Predicted-to-experimental deflection of BFRP RC members according to various international design codes

\begin{tabular}{|c|c|c|c|c|c|c|c|c|c|c|c|c|c|}
\hline \multirow{3}{*}{ Specimen } & \multirow{2}{*}{\multicolumn{3}{|c|}{$\begin{array}{c}\text { Experiment } \\
\delta_{\exp }\end{array}$}} & \multicolumn{4}{|c|}{ ACI 440.1R-06 [16] } & \multirow{2}{*}{\multicolumn{2}{|c|}{$\begin{array}{c}\text { CSA S806-02 [17] } \\
\delta_{\mathrm{CSA}} / \boldsymbol{\delta}_{\exp } \\
\end{array}$}} & \multirow{2}{*}{\multicolumn{2}{|c|}{$\begin{array}{l}\mathrm{SP295}[18] \\
\delta_{\mathrm{RUS}} / \delta_{\exp } \\
\end{array}$}} & \multirow{2}{*}{\multicolumn{2}{|c|}{$\begin{array}{c}\text { Eurocode 2 [20] } \\
\boldsymbol{\delta}_{\mathrm{EC} 2} / \boldsymbol{\delta}_{\exp } \\
\end{array}$}} \\
\hline & & & & \multicolumn{2}{|c|}{$\begin{array}{c}\boldsymbol{\delta}_{\mathrm{ACI}} / \boldsymbol{\delta}_{\exp } \text { for } \\
\boldsymbol{\alpha}_{\mathbf{b}}=\mathbf{0 . 5} \\
\end{array}$} & \multicolumn{2}{|c|}{$\begin{array}{c}\boldsymbol{\delta}_{\mathrm{ACI}} / \boldsymbol{\delta}_{\exp } \text { for } \\
\boldsymbol{\alpha}_{\mathrm{b}}=\mathbf{0 . 2} \\
\end{array}$} & & & & & & \\
\hline & $\begin{array}{c}\boldsymbol{\delta}_{0.3} \\
(\mathbf{m m})\end{array}$ & $\begin{array}{c}\boldsymbol{\delta}_{0.67} \\
(\mathrm{~mm})\end{array}$ & $\begin{array}{c}\delta_{\text {ult }} \\
(\mathbf{m m})\end{array}$ & $0.3 M_{u l t}$ & $0.67 \mathrm{M}_{\text {ult }}$ & $0.3 M_{u l t}$ & $0.67 \mathrm{M}_{\text {ult }}$ & 0.3Mult & $0.67 M_{\text {ult }}$ & $0.3 M_{u l t}$ & $0.67 \mathrm{Mult}_{\text {ult }}$ & 0.3Mult & $0.67 \mathrm{M}_{\text {ult }}$ \\
\hline SA-B10-1 & 5.18 & 18.00 & 34.31 & 0.52 & 0.85 & 0.96 & 0.95 & 1.41 & 1.00 & 1.61 & 1.03 & 1.05 & 0.93 \\
\hline SA-B10-2 & 5.55 & 18.55 & 33.6 & 0.53 & 0.87 & 0.96 & 0.96 & 1.38 & 1.01 & 1.55 & 1.03 & 1.04 & 0.93 \\
\hline R-B10-1 & 6.80 & 21.62 & 40.5 & 0.41 & 0.75 & 0.76 & 0.85 & 1.15 & 0.89 & 1.30 & 0.91 & 0.85 & 0.82 \\
\hline R-B10-2 & 5.96 & 21.04 & 39.16 & 0.46 & 0.77 & 0.86 & 0.87 & 1.31 & 0.92 & 1.48 & 0.94 & 0.97 & 0.84 \\
\hline S-B10 & 1.70 & 5.78 & 9.66 & 0.56 & 0.76 & 0.56 & 0.76 & 1.13 & 0.84 & 1.32 & 0.87 & 0.77 & 0.75 \\
\hline SA-S6-1 & 1.50 & 8.83 & 21.34 & 0.24 & 0.26 & 0.58 & 0.39 & 1.78 & 1.18 & 3.37 & 0.57 & 1.40 & 1.08 \\
\hline SA-S6-2 & 2.26 & 12.26 & 28.28 & 0.25 & 0.25 & 0.58 & 0.37 & 1.44 & 0.98 & 2.53 & 0.47 & 1.34 & 0.90 \\
\hline SA-S10 & 1.87 & 7.54 & 16.36 & 0.53 & 0.37 & 1.00 & 0.42 & 1.40 & 0.99 & 1.91 & 0.47 & 1.24 & 0.91 \\
\hline R-S10 & 1.00 & 5.19 & 13.15 & 0.48 & 0.39 & 1.06 & 0.49 & 2.00 & 1.21 & 3.04 & 0.59 & 1.51 & 1.10 \\
\hline R-S12 & 1.87 & 6.54 & 13.54 & 0.44 & 0.33 & 0.82 & 0.37 & 1.01 & 0.86 & 1.44 & 0.41 & 0.89 & 0.78 \\
\hline S-S10-1 & 1.48 & 3.94 & 6.37 & 0.60 & 0.34 & 0.60 & 0.34 & 0.87 & 0.81 & 1.06 & 0.40 & 0.74 & 0.72 \\
\hline S-S10-2 & 1.20 & 3.11 & 5.52 & 0.65 & 0.42 & 0.65 & 0.42 & 1.02 & 1.00 & 1.24 & 0.48 & 0.86 & 0.89 \\
\hline \multicolumn{4}{|c|}{ Average } & 0.47 & 0.53 & 0.78 & 0.60 & 1.33 & 0.97 & 1.82 & 0.68 & 1.06 & 0.89 \\
\hline \multicolumn{4}{|c|}{ Coefficient of variation (\%) } & 26.54 & 46.27 & 23.68 & 42.33 & 24.51 & 12.72 & 41.28 & 37.09 & 24.53 & 13.24 \\
\hline
\end{tabular}


Table 5: Comparison of the experimental crack widths for BFRP RC members with the American design codes

\begin{tabular}{|c|c|c|c|c|c|}
\hline \multirow{4}{*}{ Specimen } & \multirow{4}{*}{$\begin{array}{c}\text { W }_{\text {max,Exp }} \\
(\mathbf{m m})\end{array}$} & \multicolumn{4}{|c|}{ ACI 440.1R-06 [16] } \\
\hline & & $k_{b}=0.6$ & $\mathbf{k}_{\mathrm{b}}=\mathbf{0 . 8}$ & $k_{b}=1.0$ & $k_{b}=1.72$ \\
\hline & & $\underline{\mathbf{W}_{\text {max }, \mathrm{ACI}}}$ & $\underline{\mathbf{W}_{\text {max }, A C I}}$ & $\mathbf{W}_{\text {max,ACI }}$ & $\mathbf{W}_{\max , \mathrm{ACI}}$ \\
\hline & & $\overline{\mathbf{W}_{\text {max,Exp }}}$ & $\overline{\mathbf{W}_{\max , \operatorname{Exp}}}$ & $\overline{W_{\text {max,Exp }}}$ & $\mathbf{W}_{\text {max,Exp }}$ \\
\hline SA-B10-1 & N/A & $\mathrm{N} / \mathrm{A}$ & $\mathrm{N} / \mathrm{A}$ & $\mathrm{N} / \mathrm{A}$ & $\mathrm{N} / \mathrm{A}$ \\
\hline SA-B10-2 & 0.367 & 0.63 & 0.84 & 1.04 & 1.80 \\
\hline R-B10-1 & 0.385 & 0.62 & 0.83 & 1.04 & 1.78 \\
\hline R-B10-2 & 0.46 & 0.52 & 0.69 & 0.88 & 1.49 \\
\hline S-B10-1 & N/A & N/A & N/A & $\mathrm{N} / \mathrm{A}$ & N/A \\
\hline SA-S6-1 & 0.4 & 1.63 & 2.17 & 2.71 & 4.66 \\
\hline SA-S6-2 & N/A & N/A & N/A & N/A & N/A \\
\hline SA-S10-1 & 0.18 & 2.34 & 3.12 & 3.90 & 6.71 \\
\hline R-S10-1 & 0.16 & 2.28 & 3.04 & 3.81 & 6.55 \\
\hline R-S12-1 & 0.16 & 1.93 & 2.57 & 3.22 & 5.53 \\
\hline S-S10-1 & $\mathrm{M}_{\mathrm{cr}}>\mathrm{M}_{\mathrm{a}}$ & $\mathrm{N} / \mathrm{A}$ & N/A & $\mathrm{N} / \mathrm{A}$ & $\mathrm{N} / \mathrm{A}$ \\
\hline S-S10-2 & 0.03 & 2.59 & 2.59 & 2.59 & 2.59 \\
\hline \multicolumn{2}{|c|}{ Average } & 1.57 & 1.98 & 2.40 & 3.89 \\
\hline \multicolumn{2}{|c|}{ Coefficient of variation (\%) } & 54.77 & 52.13 & 52.38 & 57.16 \\
\hline
\end{tabular}


Table 6: Comparison of the experimental crack widths for BFRP RC members with the Russian and European design codes

\begin{tabular}{|c|c|c|c|c|}
\hline \multirow{4}{*}{ Specimen } & \multirow{4}{*}{$\begin{array}{c}\text { Wmax,Exp } \\
(\mathbf{m m})\end{array}$} & \multicolumn{2}{|c|}{ SP295 [18] } & \multirow{2}{*}{$\begin{array}{c}\text { Eurocode 2 [20] } \\
\mathrm{k}_{1}=0.8\end{array}$} \\
\hline & & $\varphi_{2}=0.7$ & $\varphi_{2}=0.5$ & \\
\hline & & $\mathbf{W}_{\text {max,RUS }}$ & $\mathbf{W}_{\text {max,RUS }}$ & $\mathbf{w}_{\max , \mathrm{EC} 2}$ \\
\hline & & $\overline{\mathbf{w}_{\max , \operatorname{Exp}}}$ & $\overline{\mathbf{w}_{\text {max,Exp }}}$ & $\overline{\mathbf{w}_{\text {max,Exp }}}$ \\
\hline SA-B10-1 & $\mathrm{N} / \mathrm{A}$ & $\mathrm{N} / \mathrm{A}$ & $\mathrm{N} / \mathrm{A}$ & $\mathrm{N} / \mathrm{A}$ \\
\hline SA-B10-2 & 0.367 & 1.39 & 0.99 & 0.99 \\
\hline R-B10-1 & 0.385 & 1.37 & 0.98 & 0.99 \\
\hline R-B10-2 & 0.46 & 1.15 & 0.83 & 0.83 \\
\hline S-B10-1 & $\mathrm{N} / \mathrm{A}$ & $\mathrm{N} / \mathrm{A}$ & $\mathrm{N} / \mathrm{A}$ & $\mathrm{N} / \mathrm{A}$ \\
\hline SA-S6-1 & 0.4 & 1.60 & 1.14 & 1.17 \\
\hline SA-S6-2 & $\mathrm{N} / \mathrm{A}$ & $\mathrm{N} / \mathrm{A}$ & $\mathrm{N} / \mathrm{A}$ & $\mathrm{N} / \mathrm{A}$ \\
\hline SA-S10-1 & 0.18 & 1.42 & 1.01 & 1.41 \\
\hline R-S10-1 & 0.16 & 1.38 & 0.99 & 1.25 \\
\hline R-S12-1 & 0.16 & 0.90 & 0.65 & 1.00 \\
\hline S-S10-1 & $\mathrm{M}_{\mathrm{cr}}>\mathrm{M}_{\mathrm{a}}$ & N/A & N/A & N/A \\
\hline S-S10-2 & 0.03 & 3.05 & 3.05 & 2.33 \\
\hline \multicolumn{2}{|l|}{ Average } & 1.53 & 1.21 & 1.25 \\
\hline \multicolumn{2}{|c|}{ Coefficient of variation (\%) } & 42.26 & 63.03 & 38.03 \\
\hline
\end{tabular}


Table A.1: Experimental and theoretical cracking and ultimate moment values for the test beams by Elgabbas et al. [23]

\begin{tabular}{|l|l|l|l|l|l|l|l|l|l|l|}
\hline \multirow{2}{*}{ Test specimen } & \multicolumn{2}{|c|}{$\begin{array}{c}\text { Experiment } \\
(\mathbf{k N m})\end{array}$} & \multicolumn{2}{c|}{$\begin{array}{c}\text { ACI 440.1R-06 } \\
{[16]}\end{array}$} & \multicolumn{2}{c|}{$\begin{array}{c}\text { CSA S806-02 } \\
{[17]}\end{array}$} & \multicolumn{2}{c|}{$\begin{array}{c}\text { SP295 } \\
{[18]}\end{array}$} & \multicolumn{2}{c|}{$\begin{array}{c}\text { Eurocode 2 } \\
{[\mathbf{1 0}]}\end{array}$} \\
\cline { 2 - 12 } & $\mathbf{M}_{\text {cr,Exp }}$ & $\mathbf{M}_{\text {ult,Exp }}$ & $\frac{\mathbf{M}_{\text {cr,ACI }}}{\mathbf{M}_{\text {cr,Exp }}}$ & $\frac{\mathbf{M}_{\text {ult,ACI }}}{\mathbf{M}_{\text {ult,Exp }}}$ & $\frac{\mathbf{M}_{\text {cr,CAN }}}{\mathbf{M}_{\text {cr,Exp }}}$ & $\frac{\mathbf{M}_{\text {ult,CAN }}}{\mathbf{M}_{\text {ult,Exp }}}$ & $\frac{\mathbf{M}_{\text {cr,RUS }}}{\mathbf{M}_{\text {cr,Exp }}}$ & $\frac{\mathbf{M}_{\text {ult,RUS }}}{\mathbf{M}_{\text {ult,Exp }}}$ & $\frac{\mathbf{M}_{\text {cr,EC2 }}}{\mathbf{M}_{\text {cr,Exp }}}$ & $\frac{\mathbf{M}_{\text {ult,EC2 }}}{\mathbf{M}_{\text {ult,Exp }}}$ \\
\hline B-2\#10 & 9.03 & 52.84 & 1.34 & 0.74 & 1.30 & 0.82 & 1.03 & 0.90 & 1.21 & 0.83 \\
\hline B-4\#10 & 7.24 & 58.30 & 1.67 & 0.79 & 1.62 & 0.87 & 1.29 & 0.96 & 1.51 & 0.88 \\
\hline B-2\#12 & 9.87 & 53.72 & 1.23 & 0.86 & 1.19 & 0.95 & 0.95 & 1.05 & 1.11 & 0.96 \\
\hline B-4\#12 & 9.00 & 76.89 & 1.35 & 0.69 & 1.30 & 0.76 & 1.04 & 0.85 & 1.22 & 0.77 \\
\hline B-2\#16 & 8.09 & 69.74 & 1.50 & 0.86 & 1.45 & 0.95 & 1.16 & 1.05 & 1.36 & 0.96 \\
\hline B-4\#16 & 9.81 & 82.06 & 1.24 & 0.82 & 1.20 & 0.89 & 0.95 & 0.99 & 1.12 & 0.90 \\
\hline
\end{tabular}


Table A.2: Predicted-to-experimental deflection of BFRP RC beams tested by Elgabbas et al. [23] according to various international design codes

\begin{tabular}{|c|c|c|c|c|c|c|c|c|c|c|c|c|}
\hline \multirow{3}{*}{$\begin{array}{c}\text { Specimen } \\
{[23]}\end{array}$} & \multirow{2}{*}{\multicolumn{2}{|c|}{$\begin{array}{c}\text { Experiment } \\
\delta_{\exp }\end{array}$}} & \multicolumn{4}{|c|}{ ACI 440.1R-06 [16] } & \multirow{2}{*}{\multicolumn{2}{|c|}{$\frac{\text { CSA S806-02 [17] }}{\delta_{\mathrm{CSA}} / \delta_{\exp }}$}} & \multirow{2}{*}{\multicolumn{2}{|c|}{$\begin{array}{l}\mathrm{SP295}[18] \\
\delta_{\mathrm{RUS}} / \delta_{\exp }\end{array}$}} & \multirow{2}{*}{\multicolumn{2}{|c|}{$\begin{array}{c}\text { Eurocode } 2[20] \\
\delta_{\mathrm{EC} 2} / \boldsymbol{\delta}_{\exp }\end{array}$}} \\
\hline & & & \multicolumn{2}{|c|}{$\begin{array}{c}\boldsymbol{\delta}_{\mathrm{ACI}} / \boldsymbol{\delta}_{\exp } \text { for } \\
\boldsymbol{\alpha}_{\mathrm{b}}=\mathbf{0 . 5}\end{array}$} & \multicolumn{2}{|c|}{$\begin{array}{c}\delta_{\mathrm{ACI}} / \boldsymbol{\delta}_{\exp } \text { for } \\
\boldsymbol{\alpha}_{\mathrm{b}}=\mathbf{0 . 2} \\
\end{array}$} & & & & & & \\
\hline & $\begin{array}{c}\boldsymbol{\delta}_{0.3} \\
(\mathbf{m m})\end{array}$ & $\begin{array}{c}\delta_{0.67} \\
(\mathrm{~mm})\end{array}$ & $0.3 M_{u l t}$ & $0.67 M_{\text {ult }}$ & $0.3 M_{u l t}$ & $0.67 M_{\text {ult }}$ & $0.3 M_{u l t}$ & $0.67 M_{\text {ult }}$ & $0.3 M_{u l t}$ & $0.67 \mathrm{M}_{\text {ult }}$ & $0.3 M_{u l t}$ & $0.67 \mathrm{Mult}_{\mathrm{ult}}$ \\
\hline $\mathrm{B}-2 \# 10$ & 16 & 48.71 & 0.18 & 0.71 & 0.41 & 0.98 & 1.35 & 1.25 & 1.74 & 1.27 & 0.91 & 1.14 \\
\hline B-4\#10 & 10.74 & 36.08 & 0.36 & 0.88 & 0.75 & 1.07 & 1.52 & 1.19 & 1.82 & 1.21 & 1.11 & 1.10 \\
\hline $\mathrm{B}-2 \# 12$ & 11.65 & 39.56 & 0.25 & 0.74 & 0.56 & 0.94 & 1.35 & 1.10 & 1.71 & 1.13 & 0.93 & 1.01 \\
\hline B-4\#12 & 14.29 & 37.24 & 0.58 & 1.00 & 0.92 & 1.07 & 1.21 & 1.11 & 1.30 & 1.12 & 1.00 & 1.04 \\
\hline B-2\#16 & 11.14 & 31.2 & 0.54 & 0.92 & 0.89 & 1.00 & 1.19 & 1.03 & 1.31 & 1.05 & 0.95 & 0.97 \\
\hline B-4\#16 & 9.7 & 25.28 & 0.77 & 0.98 & 1.04 & 1.01 & 1.14 & 1.03 & 1.21 & 1.04 & 0.96 & 0.97 \\
\hline
\end{tabular}


